\title{
Numerical analysis of the thermal and thermodynamic performance of a parabolic trough solar collector using SWCNTs-Therminol®VP-1 nanofluid
}

\author{
Aggrey Mwesigye ${ }^{1, \uparrow}$, İbrahim Halil Yılmaz ${ }^{2}$,Josua P. Meyer ${ }^{3}$ \\ ${ }^{1}$ School of Mechanical, Industrial and Aeronautical Engineering, University of the Witwatersrand, Johannesburg, \\ Private Bag 3, Wits 2050, Johannesburg, South Africa \\ ${ }^{2}$ Department of Automotive Engineering, Adana Science and Technology University, Adana, Turkey \\ ${ }^{3}$ Department of Mechanical and Aeronautical Engineering, University of Pretoria \\ Private Bag X20, Hatfield 0028, South Africa
}

\section{Highlights}

- Thermal and thermodynamic analysis of a parabolic trough collector using SWCNTTherminol ${ }^{\circledR} \mathrm{VP}-1$.

- Monte Carlo raytracing is used together with a finite volume based computational fluid dynamics tool.

- Entropy generation rates due to heat transfer and fluid flow irreversibilities are determined.

- Significant increase in the heat transfer rates with corresponding reduction in entropy generation.

- Increase in thermal efficience is lower than that of $\mathrm{Cu}, \mathrm{Ag}$ nanoparticles with Therminol ${ }^{\circledR} \mathrm{VP}-1$.

\begin{abstract}
In this paper, energetic and exergetic performances of a parabolic trough solar collector using single-walled carbon nanotubes (SWCNTs)-Therminol® VP-1 nanofluid were numerically investigated and presented. The main objective of this investigation was to determine the influence of high thermal conductivity SWCNTs suspended in the widely used heat transfer fluid, Therminol®VP-1 on the performance indicators of the parabolic trough solar collector. A parabolic trough system with a high concentration ratio of 113 was analyzed in this study. The thermo-physical properties of SWCNTs were taken as functions of nanotube length nanotube diameter, and temperature, while the properties of Therminol®VP-1 were considered to be temperature dependent. The study involved the determination of actual heat flux profile through
\end{abstract}

\footnotetext{
${ }^{\dagger}$ Corresponding author: Tel: +27 11717 7378, Fax: +27 117177049

Email address: Aggrey.Mwesigye@wits.ac.za
} 
Monte Carlo ray tracing and the subsequent coupling of this heat flux profile to a computational fluid dynamics tool using user defined functions. The computational fluid dynamics tool was finite volume based, and the realizable $k-\varepsilon$ model together with enhanced wall treatment were used for turbulence modeling. The entropy generation rates were obtained directly from the local velocity and temperature fields of the computed domain and later used in the exergy analysis. Results showed that although the heat transfer performance significantly improved with the use of SWCNTs, the increase in the thermal efficiency was not substantial. For the considered range of parameters, while the heat transfer performance increased up to $234 \%$, the thermal efficiency increased around $4.4 \%$ as the volume fraction increased from 0 to $2.5 \%$. The corresponding reduction in the entropy generation was about $70 \%$.

Keywords: SWCNT, parabolic trough receiver, Monte Carlo ray tracing, thermal efficiency, exergetic performance

\section{NOMENCLATURE}

$a \quad$ Aperture width, $\mathrm{m}$

$A_{a} \quad$ Collector's projected aperture area, $\mathrm{m}^{2}$

$A_{r} \quad$ Projected absorber tube area, $\mathrm{m}^{2}$

$c_{p} \quad$ Specific heat capacity, $\mathrm{J} \mathrm{kg}^{-1} \mathrm{~K}^{-1}$

$C_{R} \quad$ Concentration ratio

$C_{\mu} \quad$ Turbulent model constant

$d_{C N T} \quad$ Diameter of the carbon nanotube, $\mathrm{nm}$

$d_{g i} \quad$ Glass cover inner diameter, $\mathrm{m}$

$d_{g o} \quad$ Glass cover outer diameter, $\mathrm{m}$

$d_{r i} \quad$ Absorber tube's inner diameter, $\mathrm{m}$

$d_{r o} \quad$ Absorber tube's outer diameter, $\mathrm{m}$

$f \quad$ Focal length, $m$ or friction coefficient

$h \quad$ Heat transfer coefficient, $\mathrm{W} \mathrm{m}{ }^{-2} \mathrm{~K}^{-1}$

$h_{w} \quad$ Glass cover heat transfer coefficient, $\mathrm{Wm}^{-2} \mathrm{~K}^{-1}$

$I_{b} \quad$ Direct solar radiation, $\mathrm{W} \mathrm{m}^{-2}$

$k \quad$ Turbulent kinetic energy, $\mathrm{m}^{2} \mathrm{~s}^{-2}$

$L \quad$ Length, m

$L_{C N T} \quad$ Nanotube length, $\mu \mathrm{m}$ 


\begin{tabular}{|c|c|}
\hline$\dot{m}$ & Mass flow rate, $\mathrm{kg} \mathrm{s}^{-1}$ \\
\hline$P$ & Pressure, $\mathrm{Pa}$ \\
\hline$P_{p}$ & Pumping power, $\mathrm{W}$ \\
\hline $\operatorname{Pr}$ & Prandtl number \\
\hline$q^{\prime \prime}$ & Heat flux, $\mathrm{W} \mathrm{m}^{-2}$ \\
\hline$\dot{Q}_{u}$ & Useful heat gain, $\mathrm{W}$ \\
\hline$\dot{Q}_{l o s s}$ & Useful heat gain, W \\
\hline$r$ & radius, $m$ or radial position \\
\hline $\operatorname{Re}$ & Reynolds number \\
\hline$R_{K}$ & Interface thermal resistance, $\mathrm{m}^{2} \mathrm{~K} \mathrm{~W}^{-1}$ \\
\hline$S_{g e n}^{\prime}$ & Entropy generation rate per unit length, $\mathrm{W} \mathrm{m}{ }^{-1} \mathrm{~K}^{-1}$ \\
\hline$S^{\prime \prime \prime}{ }_{\text {gen }}$ & Volumetric entropy generation rate, $\mathrm{W} \mathrm{m} \mathrm{m}^{-3} \mathrm{~K}^{-1}$ \\
\hline SWCNTs & Single-walled carbon nanotubes \\
\hline$T$ & Temperature, $\mathrm{K}$ \\
\hline$u, v, w$ & Velocity components, $\mathrm{m} \mathrm{s}^{-1}$ \\
\hline$u_{i}, u_{j}$ & Velocity, $\mathrm{m} \mathrm{s}^{-1}$ \\
\hline$u_{i}^{\prime}, u_{j}^{\prime}$ & Velocity fluctuations, $\mathrm{m} \mathrm{s}^{-1}$ \\
\hline $\bar{u}_{i}, \bar{u}_{j}$ & Time-averaged velocity components, $\mathrm{m} \mathrm{s}^{-1}$ \\
\hline$u_{m}$ & Mean velocity, $\mathrm{m} \mathrm{s}^{-1}$ \\
\hline$V_{w}$ & Wind velocity, $\mathrm{m} \mathrm{s}^{-1}$ \\
\hline$\dot{V}$ & Volumetric flow rate, $\mathrm{m}^{3} \mathrm{~h}^{-1}$ \\
\hline$x_{i}, x_{j}, x_{k}$ & Spatial coordinates, $\mathrm{m}$ \\
\hline$x, y, z$ & Cartesian coordinates \\
\hline$y^{+}$ & Dimensionless wall coordinate $=y u_{\tau} / \nu$ \\
\hline$-\rho \overline{u_{i}^{\prime} u_{j}^{\prime}}$ & Reynolds stresses, $\mathrm{N} \mathrm{m}^{-2}$ \\
\hline$\Delta \mathrm{P}$ & Pressure drop, $\mathrm{Pa}$ \\
\hline
\end{tabular}

\section{Greek letters}

$\alpha_{a b s} \quad$ Absorber tube absorptivity

$\delta_{i j} \quad$ Kronecker delta 


\begin{tabular}{ll}
$\Gamma$ & Shape factor in the thermal conductivity model \\
$\varepsilon$ & Turbulent dissipation rate, $\mathrm{m}^{2} \mathrm{~s}^{-3}$ \\
$\varepsilon_{r o}$ & Absorber tube emissivity \\
$\eta_{e l}$ & Electrical efficiency, $\%$ \\
$\eta_{t h}$ & Thermal efficiency, $\%$ \\
$\theta$ & Absorber tube circumferential angle, degrees \\
$\kappa$ & Shape factor in the viscosity model \\
$\lambda$ & Thermal conductivity, $\mathrm{Wm}^{-1} \mathrm{~K}^{-1}$ \\
$\mu$ & Viscosity, Pa s \\
$\mu_{t}$ & Turbulent/Eddy viscosity, Pa s \\
$\mu_{e f f}$ & Effective viscosity, Pa s \\
$\sigma_{h . t}$ & Turbulent Prandtl number for energy \\
$\nu$ & Kinematic viscosity, $\mathrm{m}^{2} \mathrm{~s}^{-1}$ \\
$\rho$ & Density, kg $\mathrm{m}^{-3}$ \\
$\sigma_{\text {slope }}$ & Collector slope error, mrad \\
$\sigma_{\text {spec }}$ & Collector specularity error, mrad \\
$\tau_{g}$ & Glass cover transmissivity \\
$\tau_{w}$ & Wall shear stress, $\mathrm{N} \mathrm{m}{ }^{-2}$ \\
$\varphi_{r}$ & Rim angle, degrees \\
$\varphi$ & Nanoparticle volume fraction, $\%$ or rim angle \\
$\rho$ & Collector reflectivity \\
\hline
\end{tabular}

\section{Subscripts}

abs Absorber tube

amb Ambient state

$b \quad$ Bulk fluid state

bf Base fluid

c Carbon nanotube

CNT Carbon nanotube

$f \quad$ Fluid

gi Glass cover inner wall

go Glass cover outer wall 


$\begin{array}{ll}\text { in } & \text { Inlet } \\ i, j, k & \text { General spatial indices } \\ n f & \text { Nanofluid } \\ \text { out } & \text { Outlet } \\ r i & \text { Absorber tube inner wall } \\ r o & \text { Absorber tube outer wall } \\ s k y & \text { Sky } \\ t & \text { Turbulent }\end{array}$

\section{Superscripts}

Averaged value

Dimensionless value

\section{Introduction}

Solar energy, as a source of the energy, is clean, inexhaustible, and plentiful; it has certain drawbacks though [1], such as intermittent characteristic in time, not equally distributed around the world, and requiring higher capital cost to be implemented. These are generally viewed as challenges still hindering the widespread utilization of solar energy. However, the several energy challenges faced today, such as increasing demand for modern energy services, need to ensure security of energy supplies, increasing need to limit emission of greenhouse gases into the atmosphere, to curb climate change due to global warming, has intensified the search for clean and renewable energy sources. Since 1990, renewable energy sources have contributed a much higher growth rate to the world's total primary energy supply [2]. This growth has been particularly high for solar energy, which grew at average annual rates of $57.9 \%$ relative to the other renewable energy sources [2] and is forecasted to increase in the posterior years.

Current concentrating solar power (CSP) technologies are destined to support both reducing the cost of solar energy and supplying power on demand using thermal storage. Several research and development projects on CSP have shown the possibility of lower capital costs, increased efficiency, and improved reliability compared to current state-of-the-art technologies. These projects explore innovative concepts for advancing the state-of-the-art designs for the collector, receiver, heat transfer fluids (HTFs), thermal storage, and power cycle subsystems [3-6]. 
The parabolic trough solar collector (PTSC) systems are the most proven technology, hence they are widely used relative to the other CSP systems. The technology is becoming prevalent around the world and makes up over $80 \%$ of all the CSP systems available [6]. Nonetheless, several performance barriers are available in front of these systems such as low efficiency and temperature limitations. A large parabolic trough CSP plant has a mean annual solar-to-electric efficiency of $15 \%$ [7]. Today's most advanced thermal oil-based parabolic trough CSP system has the highest operating temperature of about $390^{\circ} \mathrm{C}$ [8]. Increasing the temperature to higher levels will lead higher efficiencies, but current thermal oil based HTFs degrade at temperatures above $400^{\circ} \mathrm{C}[9,10]$. Although new pathways for overcoming the temperature limitations are now under development, a majority of the projects recently completed or under development are still thermal oil-based [6]. To increase the thermal and thermodynamic performance of thermal oilbased PTSC systems, convective heat transfer enhancement in the receiver's absorber tube has been shown to be an effective way [11].

Recently, several researchers have considered the use of nanofluids to improve the optical and heat transfer performance within the absorber tube of the receiver. This innovative approach is based on the fact that suspension of nano sized particles with relatively higher thermal conductivities in the conventional thermal oil improves the thermal transport properties of the thermal oil and consequently the heat transfer coefficients for the conventional receivers [12,13].

The effects of nanofluids on the performance of PTSCs have been considered by several researchers. Sokhansefat et al. [14] numerically studied the convection heat transfer enhancement of $\mathrm{Al}_{2} \mathrm{O}_{3}$-Syltherm800 nanofluid pair in the LS-2 PTSC. The results showed that the heat transfer coefficient can be increased by $14 \%$ at $300 \mathrm{~K}$, but it lowers to $6 \%$ at $500 \mathrm{~K}$.

Basbous et al. [15] numerically investigated the thermal performance of a PTSC using $\mathrm{Al}_{2} \mathrm{O}_{3^{-}}$ Syltherm800 nanofluid. The convection heat transfer coefficient increased up to $18 \%$ at $350^{\circ} \mathrm{C}$ by adding $5 \% \mathrm{Al}_{2} \mathrm{O}_{3}$ in Syltherm800. The corresponding heat loss was lowered by as much as 10\%. Bellos and Tzivanidis [12] investigated the use of $\mathrm{Al}_{2} \mathrm{O}_{3}$-Syltherm800 and CuOSyltherm800 nanofluids in PTSCs for inlet temperature ranging from $25^{\circ} \mathrm{C}$ to $325^{\circ} \mathrm{C}$. The use of $\mathrm{CuO}$ increased the thermal efficiency up to $1.26 \%$ while using $\mathrm{Al}_{2} \mathrm{O}_{3}$ increased it up to $1.13 \%$ at the maximized concentration ratio and minimized flow rate. In another study, Bellos et al. [16] 
simulated the flow characteristics of a commercial PTSC using nanofluids and convergingdiverging absorber tube. It was shown that the use of $2 \% \mathrm{Al}_{2} \mathrm{O}_{3}$ nanoparticles inside the thermal oil and pressurized water improves the mean efficiency by $4.25 \%$ and $6.34 \%$, respectively.

Wang et al. [17] investigated the thermal performance of a PTSC with $\mathrm{Al}_{2} \mathrm{O}_{3}$-Dowtherm A nanofluid. The collector efficiency was improved by $1.2 \%$ with an inlet temperature of $650 \mathrm{~K}$. Kaloudis et al. [18] conducted a numerical study to examine the contribution of $\mathrm{Al}_{2} \mathrm{O}_{3^{-}}$ Syltherm800 nanofluid on the performance enhancement of the LS-2 collector with a solid plug. The collector efficiency increased up to $10 \%$ with a nanoparticle volume fraction of $4 \%$. Ghasemi and Ranjbar [19] numerically investigated the performance of a PTSC using $\mathrm{Al}_{2} \mathrm{O}_{3^{-}}$ Water and $\mathrm{CuO}-$ Water nanofluids. The heat transfer coefficient was shown to increase up to $28 \%$ and $35 \%$ respectively for the investigated nanofluids with volume fractions of $3 \%$. Coccia et al. [20] investigated the effects of six water-based nanofluids: $\mathrm{Fe}_{2} \mathrm{O}_{3}, \mathrm{SiO}_{2}, \mathrm{TiO}_{2}, \mathrm{ZnO}, \mathrm{Al}_{2} \mathrm{O}_{3}$ and $\mathrm{Au}$ at different weight concentrations on the thermal efficiency of a PTSC. Results indicated that only $\mathrm{Au}, \mathrm{TiO}_{2}, \mathrm{ZnO}$, and $\mathrm{Al}_{2} \mathrm{O}_{3}$ nanofluids at the lower concentrations improved the efficiency slightly compared to the base fluid.

Mwesigye et al. [21-23] performed a number of numerical studies on the thermodynamic and heat transfer performance of PTSCs with various nanofluids. Mwesigye and Huan [21] presented the thermal and thermodynamic performance of a PTSC with $\mathrm{Al}_{2} \mathrm{O}_{3}$-Syltherm800 nanofluid. The heat transfer performance increases up to $76 \%$ as the volume fraction increases from 0 to $8 \%$. It was illustrated that there is a limiting Reynolds number beyond which the use of nanofluids is not useful thermodynamically for a given inlet temperature. Mwesigye et al. [22] investigated the thermal and thermodynamic performance of a PTSC with a high concentration ratio using $\mathrm{Cu}$ Therminol® VP-1 nanofluid. Substantial improvements in the thermal performance were demonstrated. Recently, Mwesigye and Meyer [23] investigated the optimum thermal and thermodynamic operating conditions of a PTSC with a concentration ratio of 113 working with $\mathrm{Cu}$-Therminol ${ }^{2} \mathrm{VP}-1, \quad \mathrm{Ag}$-Therminol@VP-1, and $\mathrm{Al}_{2} \mathrm{O}_{3}$-Therminol ${ }$ VP-1 nanofluids. The thermal efficiency was enhanced up to $13.9 \%, 12.5 \%$, and $7.2 \%$, respectively.

De Risi et al. [24] proposed the direct absorption PTSC working with $\mathrm{CuO}$ and Ni pair gas-based nanofluids. The maximum thermal efficiency of $62.5 \%$ was obtained for the considered 
parameters. Kasaeian et al. [25] compared the performance of multi-wall carbon nanotube (MWCNT) and nanosilica nanoparticles dispersed in ethylene glycol. MWCNT-ethylene glycol achieved about $12 \%$ higher thermal efficiency than the nanoslica-ethylene glycol nanofluid.

There are few experimental studies including the use of nanofluids in PTSCs that have been presented in the open literature. Sunil et al. [26] performed an experimental study to investigate the performance of a PTSC at different flow rates using $\mathrm{SiO}_{2}$-Water nanofluid at concentrations of $0.01 \%$ and $0.05 \%$. Relatively higher efficiencies were obtained at higher flow rates for $\mathrm{SiO}_{2}-$ Water nanofluid. Kasaeian et al. [27] designed and manufactured a $1.4 \mathrm{~m}^{2}$ PTSC having an evacuated receiver with the black chrome coated copper absorber tube. The overall efficiency of the PTSC was improved by about 4 to $5 \%$ and 5 to $7 \%$, respectively in case of $0.2 \%$ and $0.3 \%$ MWCNT-mineral oil nanofluid.

Accordingly, from the reviewed literature, there is a general consensus that the higher the thermal conductivity of the nanoparticles used is, the higher the thermal performance obtained. For instance, single-walled carbon nanotubes (SWCNTs) have significantly higher thermal conductivities, about $2725 \mathrm{~W} \mathrm{~m}^{-1} \cdot \mathrm{K}^{-1}$ at $400 \mathrm{~K}$ and are expected to yield better thermal transport properties and thus higher thermal performance. Said et al. [28] obtained $15.33 \%$ improvement in the heat transfer coefficient using SWCNTs-water nanofluids in a flat plate solar collector with volume fractions up to 3.4\%. Sabiha et al. [29] experimentally investigated the performance of an evacuated tube solar collector using SWCNT nanofluids. The thermal efficiency was found to be $71.84 \%$ higher with the SWCNT nanofluid than with only water.

As the literature clearly shows, different nanofluids have been applied to PTSCs, however, there are still different nanoparticles such carbon nanotubes and nanohorns that could be worthy of being investigated due to their exceptional thermo-physical properties. Moreover, though most studies have considered the thermal performance of PTSCs using nanofluids, the studies on the thermodynamic performance are rare in the literature. In addition to increasing the heat transfer performance, the use of nanofluids affects the thermodynamic irreversibilities in these systems. For this reason, it is essential to characterize and discuss the thermodynamic performance of PTSCs with nanofluids. Thereby, the thermal and thermodynamic performances of a high concentration ratio PTSC using SWCNT-Therminol®VP-1 nanofluid are presented in this study. 


\section{Physical model}

\subsection{Parabolic trough geometry}

The precise specification of the PTSC geometry is essential to accurately model the optical performance of the system in order to obtain the heat flux distribution on the receiver's absorber tube. The heat flux distribution is then used as a realistic thermal boundary condition on the receiver's absorber tube throughout the thermal and thermodynamic analysis. Figure 1 shows the profile of a PTSC with a receiver tube at its focus. The profile of the collector is parabolic in shape and is formulated by $[30,31]$ as given by Eq. (1)

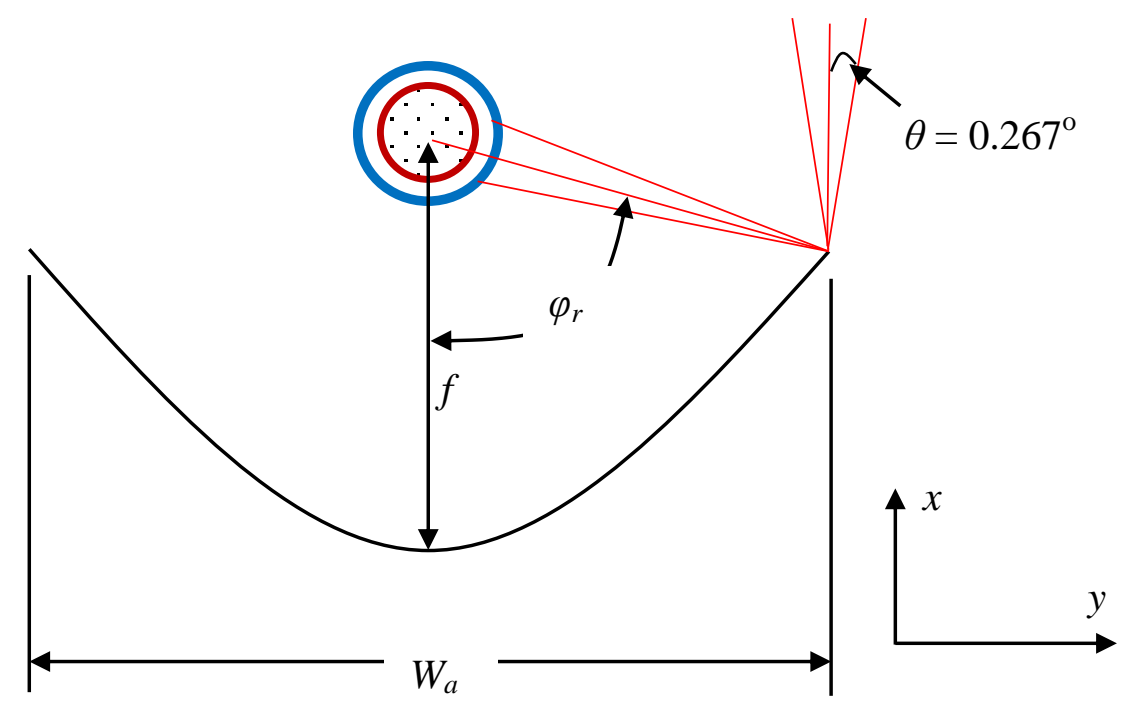

Fig. 1. Parabolic trough geometry

$$
x^{2}=4 y f
$$

where $f$ is the focal length of the collector, and $x$ and $y$ represent the Cartesian coordinate system used as shown in Fig. 1. The focal length is related to the aperture width and rim angle as 


$$
f=W_{a} / 4 \tan \left(\varphi_{r} / 2\right)
$$

In which $W_{a}$ is the collector's aperture width, and $\varphi_{r}$ is the collector's rim angle. The rim angle is determined to be

$$
\varphi_{r}=\tan ^{-1}\left[\frac{8\left(f / W_{a}\right)}{16\left(f / W_{a}\right)^{2}-1}\right]=\sin ^{-1}\left(\frac{W_{a}}{2 r_{r}}\right)
$$

In Eq. (3), $r_{r}$ is the rim radius obtained at the point where $\varphi=\varphi_{r}$. The local mirror radius at any point on the collector is given by

$$
r=\frac{2 f}{1+\cos \varphi}
$$

Thus, when the rim angle $\varphi=\varphi_{r}$, the rim radius $r_{r}$ becomes

$$
r_{r}=\frac{2 f}{1+\cos \varphi_{r}}
$$

In Fig. 1, the half angle of the cone representing the incident beam of solar radiation is $0.267^{\circ}$ as shown. Equations (1)-(5) are essential in the design and manufacture of solar parabolic trough systems. In this study, these equations were used to specify the geometry of the PTSC used to obtain accurate optical performance and a precise heat flux distribution on the receiver's absorber tube during ray tracing.

\subsection{The receiver tube}

The receiver tube, also called the heat collection element, located at the collector's focal point is central to the performance of the entire system. The overall thermal performance of the entire system depends on the design, state and condition of the receiver. The conventional receiver tube consists of an absorber tube enclosed in a glass envelope, and the space between the absorber tube and the glass envelope is evacuated to very low pressures in the order of $0.0103 \mathrm{~Pa}$ [5]. This creates a vacuum that leads to suppression of convection heat losses. The absorber tube is further coated with a selective coating with a high solar absorptivity and a lower emissivity to minimize radiation heat losses from the absorber tube since it operates at temperatures higher than those of the surroundings. Figure 2 shows the cross section of the receiver tube with the possible heat transfer mechanisms. 
The receiver involves design features such as glass-to-metal seals and metal bellows which help to accommodate the thermal expansion difference between the absorber tube and the glass envelope, and a getter material is used to absorb hydrogen diffusing into the evacuated space [5]. The accumulation of hydrogen in the annulus space makes the performance of the receiver worse since it considerably increases the receiver thermal loss [32,33].

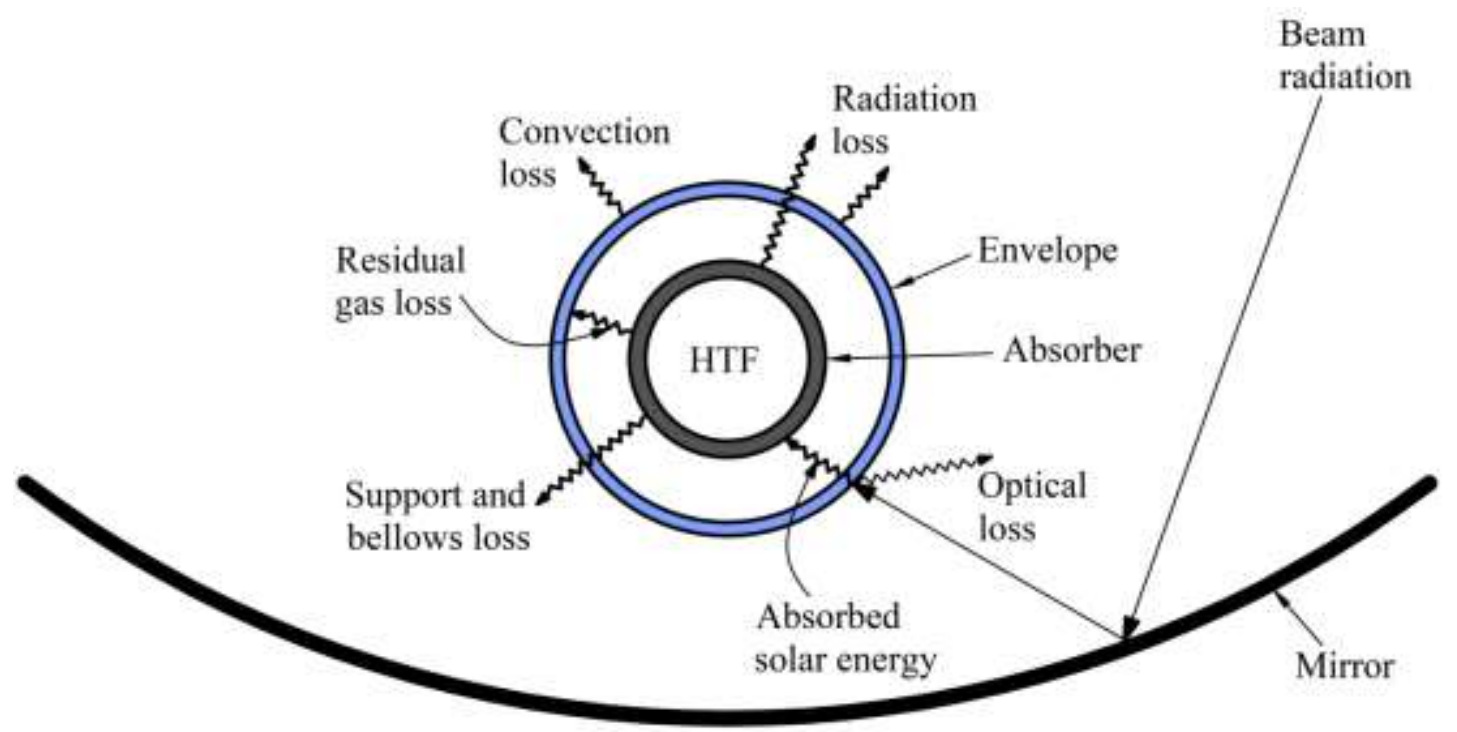

Fig. 2. A typical parabolic trough receiver and the corresponding heat losses

\subsection{Computational domain}

The parabolic trough geometry shown in Fig.1, together with the equations presented were used to model the optical performance of the system using Monte Carlo ray tracing (MCRT). Using the obtained optical performance and the heat flux profile on the receiver, the computational fluid dynamics model was developed to investigate the thermal and thermodynamic performance of the system with SWCNTs-Therminol®VP-1 nanofluid. For this purpose, the computational domain used is shown in Fig. 3. Only one half of the receiver was considered due to the symmetrical distribution of the heat flux on the absorber tube of the receiver. Even if this condition is achieved at normal incidence or with complete 2-axis tracking, it was deemed suitable for comparison purposes to analyze the influence of using nanofluids on the thermal and thermodynamic performance of the receiver. Moreover, with this assumption, it was shown that thermal performance results closely agree with experimental values as shown in the previous studies [34-36]. 


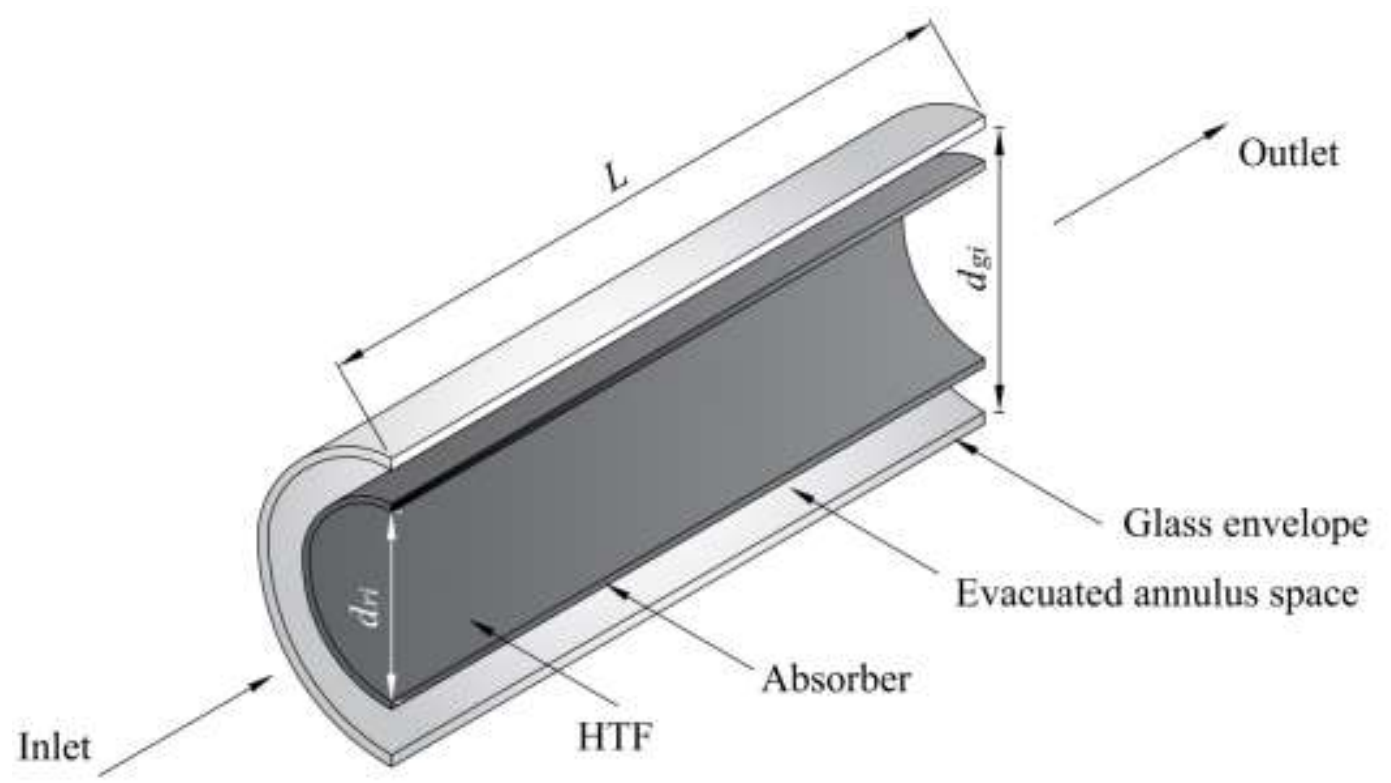

Fig. 3. Computational domain used in the numerical analysis

\section{Theoretical background and mathematical modeling}

In this section the mathematical models for the analysis of the optical, thermal and thermodynamic performances of the parabolic trough receiver are presented. Moreover, the models used for the thermal physical properties of SWCNT-Therminol®VP-1 nanofluid are presented.

\subsection{Thermal analysis}

The thermal performance of a PTSC system is centered on the analysis of the key component the receiver. In the analysis of the thermal performance of a parabolic trough system, the focus is on: (i) the prediction of the heat transfer performance inside the absorber tube where a HTF, mainly thermal oil, flows transferring thermal energy from the absorber tube to the application (ii) the determination of the thermal losses from the receiver tube during operation.

The energy balance on the receiver will yield the equations essential to characterize the thermal performance and subsequently determine the thermal losses, heat transfer performance and necessary temperatures. For an inlet temperature, $T_{i n}$, the temperature of the HTF will increase as it absorbs the incident solar radiation and leave the absorber tube with an outlet temperature of $T_{\text {out }}$. The useful heat gain delivered to the specified HTF can be calculated by

$\dot{Q}_{u}=\dot{m} c_{p}\left(T_{\text {out }}-T_{i n}\right)$ 
In which, $\dot{m}$ is the mass flow rate of the HTF through the absorber tube, and $c_{p}$ is the specific heat capacity. The useful energy delivery rate can also be determined by considering an energy balance for the entire receiver according to

$$
\dot{Q}_{u}=I_{b} \eta_{o} A_{a}-\dot{Q}_{\text {loss }}=I_{b} \eta_{o} A_{a}-A_{r} U_{L}\left(T_{r}-T_{a}\right)
$$

where $I_{b}$ is the direct normal irradiance, $\eta_{o}$ is the optical efficiency, $A_{a}$ is the unshaded aperture area of the collector, $A_{r}$ is the area of the outer wall of the absorber tube, $U_{L}$ is the overall heat loss coefficient representing the heat transfer from the absorber tube to the surroundings at $T_{a}$. Considering the convection heat transfer inside the absorber tube, the energy absorbed by the HTF can also be defined by

$\dot{Q}_{u}=\pi d_{r i} h_{r i}\left(T_{r i}-T_{f}\right)$

The value of the heat transfer coefficient, $h_{r i}$ depends on the type of flow in the absorber tube. It can be obtained using the relation:

$$
h_{r i}=\mathrm{Nu} \frac{\lambda_{f}}{d_{r i}}
$$

where $\mathrm{Nu}=4.36$ if the flow is laminar, and $\lambda_{f}$ is the thermal conductivity of the HTF. When the flow is turbulent, the Nusselt number is obtainable from [37]

$$
\mathrm{Nu}=\frac{(f / 8)(\operatorname{Re}-1000) \operatorname{Pr}}{1+12.7(f / 8)^{0.5}\left(\operatorname{Pr}^{2 / 3}-1\right)}
$$

Here, $f$ is the friction coefficient and can be estimated by

$$
f=(0.790 \ln \operatorname{Re}-1.64)^{-2}
$$

Evacuating the annulus to very low pressures causes the convection heat transfer within the annulus to be suppressed. Only radiation heat transfer becomes the significant heat transfer mode. For the steady state analysis, the receiver thermal loss is accordingly given by

$$
\dot{Q}_{\text {loss }}=\frac{\sigma \pi d_{r o}\left(T_{r o}^{4}-T_{g i}^{4}\right)}{\frac{1}{\varepsilon_{r o}}+\frac{\left(1-\varepsilon_{g i}\right) d_{r o}}{\varepsilon_{g i} d_{g i}}}
$$

where $d_{r o}$ is the absorber tube outer diameter, $\varepsilon$ is the emissivity and $\sigma$ is the Stefan Boltzmann constant $=5.67 \times 10^{-8} \mathrm{Wm}^{-2} \mathrm{~K}^{-4}$. 
Under steady state conditions, the value of the thermal loss obtained using Eq. (12) becomes equal to the heat transfer through the wall of the glass envelope which is rejected from the outer wall of the glass cover by combined convection and radiation heat transfer [30]

The pumping power to overcome the pressure loss is determined to be

$P_{p}=\dot{V} \Delta P$

where $\dot{V}$ is the volume flow rate, and $\Delta P$ corresponds to pressure loss across the flow direction of the receiver.

The thermal or energetic performance of the PTSC system is related to how a portion of the incident beam radiation falling on the collector aperture is transferred to the HTF as useful heat gain. The thermal efficiency is thus defined as

$\eta_{t h}=\frac{\dot{Q}_{u}-\frac{P_{p}}{\eta_{e l}}}{I_{b} A_{a}}$

where $\eta_{e l}$ is the electrical efficiency of the power block specified as $32.7 \%$.

\subsection{Thermodynamic analysis}

In the thermodynamic analysis, the main objective is to analyze the rates of exergy destruction because of the irreversibilities occurring in the system. This requires the application of two tools: the entropy generation minimization method and the exergy analysis. In the scope of this study, the variation of entropy generation with heat transfer enhancement was determined. The entropy generation rates were considered as the heat transfer and fluid flow irreversibilities, they were determined from the temperature and velocity fields of the flow, and from the properties of the HTF as well using the entropy generation minimization method. In this method, the local entropy generation rates are obtained for each control volume in the computational domain and then integrated over the entire computational domain. The total entropy generation rate is determined as the sum of the heat transfer irreversibility and the fluid flow irreversibility [38,39]. In this analysis, the volumetric fluid flow irreversibility is given by $[38,39]$

$$
\left(S_{g e n}^{\prime \prime \prime}\right)_{F}=\frac{\mu}{\bar{T}}\left(\frac{\partial \bar{u}_{i}}{\partial x_{j}}+\frac{\partial \bar{u}_{j}}{\partial x_{i}}\right) \frac{\partial \bar{u}_{i}}{\partial x_{j}}+\frac{\rho \varepsilon}{\bar{T}}
$$


Equation (15) represents the summation of the entropy generations due to direct dissipation (laminar part) and turbulent dissipation which, in turn, are the first and the second terms on the right-hand side of the equation. In Eq. (15), $\mu$ is the dynamic viscosity of the fluid, $\rho$ is the density of the fluid, and $\varepsilon$ is the turbulent dissipation rate.

The volumetric heat transfer irreversibility is given by $[38,39]$

$$
\left(S_{g e n}^{\prime \prime \prime}\right)_{H}=\frac{\lambda}{\bar{T}^{2}}(\nabla \bar{T})^{2}+\frac{\alpha_{t}}{\alpha} \frac{\lambda}{\bar{T}^{2}}(\nabla \bar{T})^{2}
$$

where the first and the second terms of Eq. (16) represent the entropy generations by heat transfer by direct and turbulent dissipations, respectively. In Eq. (16), $\lambda$ is the fluid's thermal conductivity, and $\alpha$ and $\alpha_{t}$ in the second term represent the thermal diffusivities. Once the entropy generation rates due to fluid flow and heat transfer are obtained from Eqs. (15) and (16) respectively for each control volume, the total entropy generation rate over the entire computational domain can then be obtained by integrating them over the entire volume as

$$
S_{g e n}=\iiint_{V} S_{g e n}^{\prime \prime \prime} d V
$$

The exergy destruction rate due to these irreversibilities is then determined to be

$$
E_{D}=T_{o} S_{g e n}
$$

The availability or exergy of a system is related with the maximum useful work that can be obtained from that system as it undergoes a process and comes into equilibrium with its environment. For the PTSC system, the exergy is determined to be

$$
\dot{E}_{u}=\dot{Q}_{u}\left(1-\left(\frac{T_{o}}{T_{\text {out }}-T_{\text {in }}}\right) \times \ln \left(\frac{T_{\text {out }}}{T_{\text {in }}}\right)\right)
$$

$T_{o}$ is the dead state temperature, which was taken to be $300 \mathrm{~K}$ in the analyses, and the useful heat gain can be calculated using Eq. (6).

The exergy of the incident solar radiation is defined by Petela [40,41] as

$$
\dot{E}_{\text {sol }}=\dot{Q}_{\text {sol }}\left(1+\frac{1}{3}\left(\frac{T_{o}}{T_{\text {sun }}}\right)^{4}-\frac{4}{3}\left(\frac{T_{o}}{T_{\text {sun }}}\right)\right)
$$


where $\dot{Q}_{\text {sol }}$ is the amount of energy incident on the collector's aperture, and $T_{\text {sun }}$ is the surface temperature of the sun, taken as $5800 \mathrm{~K}[40,41]$. The exergetic efficiency is described as

$$
\eta_{e x}=\frac{\dot{E}_{u}}{\dot{E}_{s o l}}
$$

\subsection{Material properties}

\subsubsection{Heat transfer fluid}

The HTF used in the absorber tube was Therminol@VP-1. This HTF is commercially available and widely used in PTSC systems. It has a normal boiling point of $257^{\circ} \mathrm{C}$ and has an optimal usage range when in liquid phase from $12-400^{\circ} \mathrm{C}$ [9]. The thermo-physical properties of this HTF are provided in the manufacturer's data sheets [9]. These properties are the strong function of operating temperature rather than pressure. For this reason, the temperature dependency for each property was described with polynomial functions using regression analysis as below.

For $285.15 \mathrm{~K} \leq T \leq 698.15 \mathrm{~K}$,

The specific heat capacity $\left(\mathrm{J} \mathrm{kg}^{-1} \cdot \mathrm{K}^{-1}\right)$ :

$c_{p}=2.125 \times 10^{3}-11.017 T+0.049862 T^{2}-7.7663 \times 10^{-5} T^{3}+4.394 \times 10^{-8} T^{4}$

The density $\left(\mathrm{kg} \mathrm{m}^{-3}\right)$ :

$\rho=1.4386 \times 10^{3}-1.8711 T+2.737 \times 10^{-3} T^{2}-2.3793 \times 10^{-6} T^{3}$

The thermal conductivity $\left(\mathrm{W} \mathrm{m}^{-1} \mathrm{~K}^{-1}\right)$ :

$\lambda=0.14644+2.0353 \times 10^{-5} T-1.9367 \times 10^{-7} T^{2}+1.0614 \times 10^{-11} T^{3}$

The dynamic viscosity (mPa.s):

For the temperature range of $285.15 \mathrm{~K} \leq T \leq 373.15 \mathrm{~K}$,

$\mu=3.661 \times 10^{2}-3.0154 T+8.3409 \times 10^{-3} T^{2}-7.723 \times 10^{-6} T^{3}$ 
For $373.15 \mathrm{~K} \leq T \leq 698.15 \mathrm{~K}$,

$$
\mu=23.165-0.1476 T+3.617 \times 10^{-4} T^{2}-3.9844 \times 10^{-7} T^{3}+1.6543 \times 10^{-10} T^{4}
$$

\subsubsection{Nanofluid}

Single wall carbon nanotubes (SWCNTs) are considered in this study given that they have significantly higher thermal conductivities compared with most other nanoparticles. Its thermal conductivity is about $2725 \mathrm{~W} \mathrm{~m}^{-1} \mathrm{~K}^{-1}$ at $400 \mathrm{~K}$ and about $1482 \mathrm{~W} \mathrm{~m}^{-1} \mathrm{~K}^{-1}$ at $650 \mathrm{~K}$ for a $10 \mathrm{~nm}$ in diameter and $5 \mu \mathrm{m}$ length nanotube [42,43]. The thermal conductivity of some of the nanoparticles with higher thermal conductivities such as copper is about $393 \mathrm{~W} \mathrm{~m}^{-1} \mathrm{~K}^{-1}$ at $400 \mathrm{~K}$ and $376 \mathrm{~W} \mathrm{~m}^{-1} \mathrm{~K}^{-1}$ at $650 \mathrm{~K}$, while it is for silver about $425 \mathrm{~W} \mathrm{~m}^{-1} \mathrm{~K}^{-1}$ at $400 \mathrm{~K}$ and $408 \mathrm{~W} \mathrm{~m}^{-1}$ $\mathrm{K}^{-1}$ at $650 \mathrm{~K}$ [44]. Therefore, SWCNTs are expected to increase the thermal transport properties of the HTF substantially and essentially increase the thermal performance.

For the SWCNTs with diameters between 2-10 nm and length between 1-5 $\mu \mathrm{m}$, the density is in the range of $1.7-1.9 \mathrm{~g} \mathrm{~cm}^{-3}$ [45]. Change in temperature does not alter the specific heat capacity of SWCNTs appreciably. Its specific heat capacity varies between $1.79 \mathrm{~J} \mathrm{~g}^{-1} \mathrm{~K}^{-1}$ to $1.88 \mathrm{~J} \mathrm{~g}^{-1} \mathrm{~K}^{-1}$ at temperatures of $250^{\circ} \mathrm{C}$ and $400^{\circ} \mathrm{C}$, respectively [46]. The thermal conductivity of SWCNTs, $\lambda_{c}$ is a function of temperature and length and can be determined according to $[42,43]$

$\lambda_{c}=\left[3.7 \times 10^{-7} T+9.7 \times 10^{-10} T^{2}+9.3\left(1+\frac{0.5}{L_{C N T}}\right) T^{-2}\right]^{-1}$

where $T$ is the temperature in $\mathrm{K}$, and $L_{C N T}$ is the length in $\mu \mathrm{m}$. Equation (27) gives the thermal conductivity in $\mathrm{W} \mathrm{m}^{-1} \mathrm{~K}^{-1}$ and is applicable over a range of temperature from 100 to $800 \mathrm{~K}$.

In order to precisely predict the performance of a system with nanoparticle laden fluid, accurate determination of the thermal physical properties of the synthesized nanofluids becomes important. Various models have been derived and presented by several researchers. These models are widely used and yield acceptable results. The properties of the nanofluid formed mainly depend on the volume fraction of the nanotubes employed and the thermal properties of both the base fluid and the nanotubes. The density of the nanofluid is given by $[47,48]$

$\rho_{n f}=(1-\varphi) \rho_{b f}+\varphi \rho_{c}$ 
Assuming thermal equilibrium between the nanoparticles and the fluid, a formulation for the specific heat capacity was suggested as $[47,48]$

$$
c_{p, n f}=\frac{(1-\varphi) c_{p, b f} \rho_{b f}+\varphi c_{p, c} \rho_{c}}{(1-\varphi) \rho_{b f}+\varphi \rho_{c}}
$$

The viscosity of the nanofluid has been traditionally calculated using the model developed by Einstein given shown in Eq. (30) [49]. However, this model has been shown to underestimate the effective viscosity of nanofluid mixtures [50]. As such, several researchers have derived other models for the determination of the viscosity of nanofluid mixtures. Most of these models are applicable to spherical nanoparticles. Xing et al. [50,51] derived an expression that can be used to determine the nanofluid viscosity for different shapes of the nanoparticles as given by Eq. (31). This equation is of the same form as the Einstein's model [49] with a factor $\kappa$ that depends on the shape of the nanoparticle used as indicated in Table 1 [50].

$$
\begin{aligned}
& \frac{\mu_{n f}}{\mu_{b f}}=1+2.5 \varphi \\
& \frac{\mu_{n f}}{\mu_{b f}}=1+\kappa \varphi
\end{aligned}
$$

Table 1. Shape factor $\kappa$ in Eq. (31) for different shapes of particles [50]

\begin{tabular}{lcccc}
\hline Shape & Sphere & Oval & Layered structure & Rodlike \\
\hline$\kappa$ & 2.5 & 4.8 & 53 & 80
\end{tabular}

To consider the effect of different shaped nanoparticles, the Hamilton and Crosser model is usually used to determine the thermal conductivity [52]:

$$
\frac{\lambda_{n f}}{\lambda_{b f}}=\frac{\lambda_{c}+(\Gamma-1) \lambda_{b f}-(\Gamma-1) \varphi\left(\lambda_{b f}-\lambda_{c}\right)}{\lambda_{c}+(\Gamma-1) \lambda_{b f}+\varphi\left(\lambda_{b f}-\lambda_{c}\right)}
$$

The shape factor, $\Gamma$ in Eq. (32) depends on the geometry of the nanoparticle. It is taken to be 3 for spherical particles and 6 for cylindrical nanoparticles. But, this model underestimates the nanofluid thermal conductivity for cylindrical nanoparticles [50,53,54]. Nan et al. [53,54] developed and validated a more accurate model to determine the thermal conductivity of SWCNTs nanofluids. This model, which is based on the effective medium theory takes into account the diameter and the length of the nanotube as well as the interfacial thermal resistance. According to this model, the effective thermal conductivity is given by $[53,54]$ 
$\frac{\lambda_{n f}}{\lambda_{b f}}=\frac{3+\varphi\left(\beta_{x}+\beta_{z}\right)}{3-\varphi \beta_{x}}$

where

$\beta_{x}=\frac{2\left(\lambda_{11}^{c}-\lambda_{b f}\right)}{\lambda_{11}^{c}+\lambda_{b f}}$

$\beta_{z}=\lambda_{33}^{c} / \lambda_{b f}-1$

In Eqs. (34) and (35), $\varphi$ is the volume fraction, $\lambda_{11}^{c}$ and $\lambda_{33}^{c}$ represent respectively the equivalent thermal conductivities along the transverse and longitudinal axes of a composite unit cell. These terms are expressed as

$$
\begin{aligned}
& \lambda_{11}^{c}=\frac{\lambda_{c}}{1+\frac{2 a_{K} \lambda_{c}}{d_{C N T} \lambda_{b f}}} \\
& \lambda_{33}^{c}=\frac{\lambda_{c}}{1+\frac{2 a_{K} \lambda_{c}}{L_{C N T} \lambda_{b f}}}
\end{aligned}
$$

In Eqs. (34) - (37), $d_{C N T}$ and $L_{C N T}$ are the diameter and length of the nanotubes, respectively. $\lambda_{c}$ is the thermal conductivity of SWCNTs and $\lambda_{b f}$ is the thermal conductivity of the HTF. The thermal conductivity obtained using Eq. (33) is considered more accurate, it results in higher values as the diameter and length of the nanotube increase. The empirical constant, $a_{k}$ is related to the interface thermal resistance, $R_{K}[53,54]$. In this work, a suggested value of $R_{K}=8 \times 10^{-8} \mathrm{~m}^{2} \mathrm{~K} \mathrm{~W}^{-1}$ was used $[53,54]$.

$a_{K}=R_{K} \lambda_{b f}$

The volume fraction of SWCNTs in the base fluid is of importance in ensuring the stability of the resulting nanofluid. High volume fraction will affect the stability of the nanofluid leading to agglomeration and also will result in increased pumping power requirement. In this study, low values of the volume fractions up to $2.5 \%$ were considered. This is lower than values considered by Said et al. [28] (up to 3.5\%) for SWCNTs-water nanofluids in a flat plate solar collector and 
values considered by Alashkar and Gadalla [42] (up to 5\%) for SWCNTs-Therminol in a PTSC integrated solar regenerative Rankine cycle.

It should also be noted that inclusion of nanotubes in Therminol ${ }^{\circledR V P}-1$ may alter the rheological behavior of the resulting nanofluid. The debate on whether inclusion of nanoparticles or CNTs in conventional fluids will result in Newtonian or Non-Newtonian behavior is still ongoing and discrepancies still exist in the literature [55]. Agglomeration is a major factor that leads to nonNewtonian behavior of nanofliuds, especially in the lower shear region [55]. Therefore, stably dispersed and homogeneous nanofluids generally result in Newtonian behavior. This is possible with low loading of nanatubes [56,57] and use of dispersants or surfactants [58]. A Newtonian behavior was shown in the turbulent flow regime and a non-Newtonian behavior was shown in the laminar flow regime for CNTs in a horizontal tube with $0.01 \%$ weight concentration [59]. Newtonain behavior was also demonstrated for CNTs at high values of shear rate in a study by Aladag et al. [60], indicating the possibility of Newtonian behavior for nanofluids in the turbulent flow regime. Li et al. [61] performed a combined experimental and numerical investigation of volumetric versus surface solar absorbers for a concentrated solar thermal collector using MWCNTs-Therminol 55 nanofluid in the temperature range of $100-250{ }^{\circ} \mathrm{C}$. The experimental and computational fluid dynamics results were found to be in good agreement for the thermal efficiency of these two receivers under the consideration of Newtonian fluid behavior. In the study related to the viscosity of water based $\mathrm{SWCNH}$ and $\mathrm{TiO}_{2}$ nanofluids, Bobbo et al. [58] prepared nanofluids of up to $1 \%$ by mass. Suspension stability was ensured by using the high pressure homogenization method and the use of sodium dodecyl sulfate (SDS) and EPG dispersants for SWCNH and $\mathrm{TiO}_{2}$, respectively. They revealed that the resulting nanofluids were Newtonian for all the compositions considered. In a study performed by Mesgari et al. [62] on the thermal stability of carbon nanofluids for solar thermal applications, it was shown that there was no agglomeration for mildly oxidized MWCNTs dispersed in Therminol for temperatures up to $250^{\circ} \mathrm{C}$. In line with the above studies, it has been assumed that SWCNTs are stably and homogeneously dispersed in Therminol®VP-1, and the resulting nanofluid is Newtonian. Moreover, for the Reynolds numbers considered in this work, the shear rate is expected to be high, such that the viscosity of the nanofluid is independent of the shear rate. 


\subsubsection{Receiver}

For the receiver tube, a commercially available receiver was used in this study. The absorber tube material is a $321 \mathrm{H}$ stainless steel whose thermal conductivity is related with temperature as [63] $\lambda_{a b s}=0.0153 T_{a b s}+14.775$

In Eq. (39), $T_{a b s}$ is the absorber tube temperature in $\mathrm{K}$, and the unit of thermal conductivity is in $\mathrm{W} \mathrm{\textrm {m } ^ { - 1 }} \mathrm{K}^{-1}$.

The outer surface of the absorber tube has a selective coating. Cermet was used as the selective coating whose emissivity is also described as a function of temperature [64]

$\varepsilon_{r o}=0.062+2 \times 10^{-7} T_{r o}{ }^{2}$

where $T_{r o}$ is in ${ }^{\circ} \mathrm{C}$.

The absorber tube is enclosed with a glass cover made from Pyrex ${ }^{\circledR}$, its emissivity is temperature independent. The inner and outer surface emissivities of the glass cover were taken as 0.86 [63].

\section{Numerical modeling}

In this section, the numerical modeling approach implemented to obtain the thermal and thermodynamic performance of the receiver tube is presented. Although the equations presented in Section 3 can be solved analytically to obtain receiver performance, in most cases a uniform temperature profile on the receiver's absorber tube is used. Realistically, the heat flux distribution is non-uniform and varies significantly around the circumference of the absorber tube. To accurately predict the thermal and thermodynamic performances of the PTSC, a conjugate solution with MCRT and computational fluid dynamics tools was employed in this study. Using the MCRT procedure, a precise heat flux profile on the absorber's receiver tube was obtained and coupled to the computational fluid dynamics tool to satisfy the accurate determination of velocity and temperature fields in the receiver and consequently the thermal and thermodynamic performance. The ray tracing approach is discussed in Mwesigye et al. [23]. The governing equation for the numerical modeling, the boundary conditions, and the numerical modeling approach to solve the problem are presented in the next sections. 


\subsection{Governing equations}

Flow of the HTF inside the receiver's absorber tube is generally considered to be turbulent to ensure effective heat transfer performance and desirable receiver tube temperature gradients for guaranteeing safe and reliable operation of the receiver. The equations used to model this flow phenomena are [65] based on continuity, momentum, and energy balances:

Continuity:

$\frac{\partial\left(\rho \bar{u}_{i}\right)}{\partial x_{i}}=0$

Momentum:

$\frac{\partial}{\partial x_{j}}\left(\rho \bar{u}_{i} \bar{u}_{j}\right)=-\frac{\partial \bar{P}}{\partial x_{i}}+\frac{\partial}{\partial x_{j}}\left[\mu\left(\frac{\partial \bar{u}_{i}}{\partial x_{j}}+\frac{\partial \bar{u}_{j}}{\partial x_{i}}\right)-\frac{2}{3} \mu \frac{\partial \bar{u}_{i}}{\partial x_{i}} \delta_{i j}-\rho \overline{u_{i}^{\prime} u_{j}^{\prime}}\right]$

Energy:

$$
\frac{\partial}{\partial x_{j}}\left(\rho \bar{u}_{j} c_{p} \bar{T}\right)=\frac{\partial}{\partial x_{j}}\left(\lambda \frac{\partial \bar{T}}{\partial x_{j}}+\frac{\mu_{t}}{\sigma_{h, t}} \frac{\partial\left(c_{p} \bar{T}\right)}{\partial x_{j}}\right)+\bar{u}_{j} \frac{\partial \bar{P}}{\partial x_{j}}+\left[\mu\left(\frac{\partial \bar{u}_{i}}{\partial x_{j}}+\frac{\partial \bar{u}_{j}}{\partial x_{i}}\right)-\frac{2}{3} \mu \frac{\partial \bar{u}_{i}}{\partial x_{i}} \delta_{i j}-\rho \overline{u_{i}^{\prime} u_{j}^{\prime}}\right] \frac{\partial \bar{u}_{i}}{\partial x_{j}}
$$

The Reynolds stresses in Eqs. (42) and (43) are obtained using Boussinesq's hypothesis as [65]

$$
-\rho \overline{u_{i}^{\prime} u_{j}^{\prime}}=\mu_{t}\left(\frac{\partial u_{i}}{\partial x_{j}}+\frac{\partial u_{j}}{\partial x_{i}}\right)-\frac{2}{3}\left(\rho k+\mu_{t} \frac{\partial u_{k}}{\partial x_{k}}\right) \delta_{i j}
$$

In Eq. (41), $k$ is the turbulent kinetic energy per unit mass given by [65]

$$
k=\frac{1}{2}\left(\overline{u^{\prime 2}}+\overline{v^{\prime 2}}+\overline{w^{\prime 2}}\right)
$$

And $\mu_{t}$ is the eddy viscosity obtained from [65]

$\mu_{t}=\rho C_{\mu} \frac{k^{2}}{\varepsilon}$

In the above equations, $\bar{u}_{i}$ and $\bar{u}_{j}$ are the time-averaged velocity components in the $i$ and $j$ directions respectively, $\bar{T}$ is the time-averaged temperature, $\bar{P}$ is the time-averaged pressure, $\varepsilon$ is the turbulent dissipation rate and $C_{\mu}$ is an empirical relation/constant depending on the model used.

The realizable $k$ - $\varepsilon$ model was shown to accurately model the turbulent flow in the receiver's absorber tube in previous studies by Mwesigye et al. $[13,23]$. This model was again used in this 
study for turbulence modeling. In the realizable $k-\varepsilon$ model, two equations -turbulent dissipation rate and turbulent kinetic energy- are also solved together with the governing equations. The equations representing the turbulent dissipation rate and the turbulent kinetic energy and turbulence modeling using the $k-\varepsilon$ models are detailed in Ref. [65].

Within the evacuated annulus space, the only significant mode of heat transfer is radiation heat transfer [63]. It can be easily modeled using the surface to surface radiation model in ANSYS® Fluent [65] after the view factors are computed. However, in this study, this surface to surface radiation heat transfer mechanism was modeled using the discrete ordinates model [65] with air as a nonparticipating medium.

Table 2. Simulation parameters for the PTSC

\begin{tabular}{ll}
\hline Parameter & Value \\
\hline Absorber tube inner diameter, $d_{r i}(\mathrm{~m})$ & 0.076 \\
Absorber tube outer diameter, $d_{r o}(\mathrm{~m})$ & 0.080 \\
Glass cover inner diameter, $d_{g i}(\mathrm{~m})$ & 0.120 \\
Aperture width, a (m) & 9.0 \\
Receiver length, $L(\mathrm{~m})$ & 5.0 \\
Inlet temperatures, $T_{\text {in }}(\mathrm{K})$ & $400-650$ \\
Flow rates, $\mathrm{m}^{3} \mathrm{~h}^{-1}$ & $1.63-69.41$ \\
Direct normal solar irradiance, $I_{b}\left(\mathrm{~W} \mathrm{~m}^{-2}\right)$ & \\
Geometrical concentration ratio, $C_{R}$ & 113 \\
Rim angle, $\varphi_{r}$ & 8000 \\
Absorber tube absorptivity, $\alpha_{a b s}$ & 0.96 \\
Collector reflectivity, $\rho$ & 0.96 \\
Glass cover transmissivity, $\tau_{g}$ & 0.97 \\
Slope error, $\sigma_{\text {slope }}$ & $3 \mathrm{mrad}$ \\
Specularity error, $\sigma_{s p e c}$ & $0.5 \mathrm{mrad}$ \\
$L_{C N T}$ & $10 \mathrm{~nm}$ \\
$d_{C N T}$ & $5 \mu \mathrm{m}$ \\
\hline
\end{tabular}

\subsection{Simulation parameters and boundary conditions}

The geometrical, optical, environmental properties, and the flow parameters shown in Table 2 were used in the model for the determination of the optical, thermal and thermodynamic 
performance of the PTSC system. The geometrical concentration ratio used is described as the ratio of projected collector area $\left(A_{a}=a L\right)$ to the projected area of the absorber tube $\left(A_{r}=d_{r o} L\right)$.

The boundary conditions used in the numerical modeling of the computational fluid dynamics

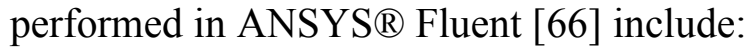

i. A non-uniform heat flux profile on the receiver's absorber tube: This heat flux profile was obtained following the Monte Carlo ray tracing procedure in SolTrace [67] as described in Mwesigye et al. [23]. In the computational fluid dynamics analysis, this heat flux profile is hooked on the receiver's absorber tube with user defined functions (UDFs). The heat flux profile on the half of the receiver tube $-90^{\circ} \leq \theta \leq+90^{\circ}$ is shown in Fig. 4 . The heat flux profile was obtained under the case of the slope error of $3 \mathrm{mrad}$ which is close to what is expected in realistic systems [68] a specularity error of $0.5 \mathrm{mrad}$.

ii. An inlet boundary condition was specified at the inlet of the absorber tube, $z=0$, $-90^{\circ} \leq \theta \leq+90^{\circ} u_{z}=u_{i n}, u_{x}=0, u_{y}=0$ and $T=T_{i n}$.

iii. A pressure outlet boundary condition was specified at the outlet of the absorber tube, $z=L$, $-90^{\circ} \leq \theta \leq+90^{\circ}$ since the flow is fully developed at the outlet, a pressure gradient equal to zero was specified.

iv. All receiver walls, $0 \leq z \leq L$ (absorber tube $r=d_{r i} / 2$ and $r=d_{r o} / 2$; glass cover, $r=d_{g i} / 2$ and $r=d_{g o} / 2$ ) were modeled with no-slip and no penetration boundary conditions. The specific thermal boundary conditions:

a. Non-uniform heat flux boundary condition for the absorber tube outer wall already defined in (i) above.

$b$. A mixed convection and radiation boundary condition for the receiver tube's outer wall was specified. A convection heat transfer coefficient, $h_{w}$ in Eq. (47) [69] was specified and the radiation heat transfer was modeled using Stefan Boltzmann law by specifying the sky temperature as given by Eq.(10) [70]

$$
\begin{aligned}
& h_{w}=V_{w}^{0.58} d_{g o}^{-0.42} \\
& T_{s k y}=0.0552 T_{a m b}^{1.5}
\end{aligned}
$$


In this study, the ambient temperature, $T_{a m b}$ was maintained at $300 \mathrm{~K}$, and the wind velocity, $V_{w}$ was kept at $2 \mathrm{~m} / \mathrm{s}$.

v. For the receiver's annulus space, zero values of all gradients were ensured using symmetry boundary conditions for the inlet and outlet of the annulus space since there is no flow due to the presence of vacuum.

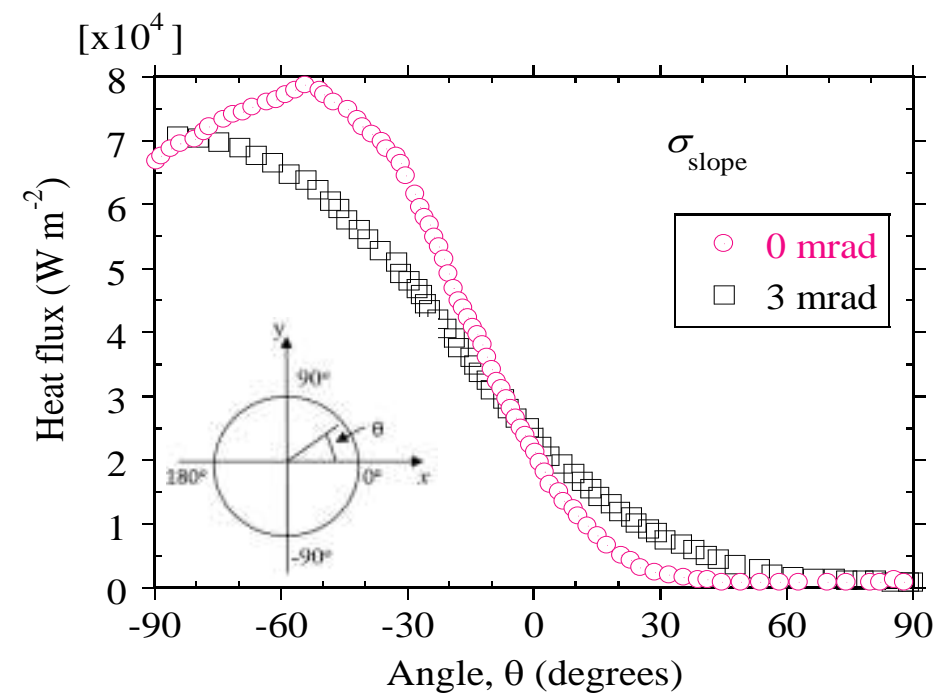

Fig. 4. Variation of heat flux on the circumference of the absorber tube with slope errors

\subsection{Procedure of numerical solution}

The determination of the thermal and thermodynamic performance of a parabolic trough receiver using Therminol®VP-1 was performed in a number of stages. Firstly, Monte Carlo ray tracing using SolTrace [67] was used to determine the optical performance of the system according to the detailed procedure given by Mwesigye et al. [23,35]. The parabolic trough geometry was determined using Eqs.(1)-(5), the optical properties of the collector (reflectivity), the receiver tube (glass cover transmissivity, absorber tube absorptivity), and the sun (sun shape) were specified as presented in Table 2. The receiver tube used in this study has characteristics of the fourth-generation Schott solar PTR ${ }^{\circledR} 70$ receivers [71]. The absorptivity of the absorber tube was 0.96, the glass cover transmissivity was 0.97 and the collector mirror reflectivity was 0.96 . As expected in actual parabolic trough plants, the slope error used was $3 \mathrm{mrad}$, and the specularity error was taken as $0.5 \mathrm{mrad}$ [68]. Using these parameters, a Monte Carlo ray tracing model was developed and solved using SolTrace [67]. Employing the number of sun generated rays as $1 \times 10^{8}$ and the number of desired ray intersections as $1 \times 10^{6}$, a precise optical solution was 
achieved. The heat flux profiles for two different slope error values are shown in Fig. 4. It should be noted that the heat flux profile obtained under $3 \mathrm{mrad}$ was considered in the latter analyses.

Once the precise heat flux profile was obtained, the second step was the development of the numerical model for the investigation of the thermal and thermodynamic performance. This model was developed and implemented in ANSYS ${ }^{\circledR} 17.1$ [66]. The model was built in ANSYS Design Modeler, including the CAD model of the computational domain. The discretization of the computational domain was performed with the ANSYS Meshing tool. The equations representing the continuity, momentum and energy balances, and turbulence models Eq. (41)(46), and the boundary conditions presented in Section 4.2 were solved simultaneously by implementing them into ANSYS Fluent [66]. The SIMPLE algorithm was used for coupling of pressure and velocity, the second-order upwind schemes were used for integrating the governing equations over the computational domain. For turbulence modeling, the realizable k- $\varepsilon$ was preferred to model the heat transfer and fluid flow in the receiver with acceptable accuracy. With lower $y^{+}$values, the enhanced wall treatment option was selected to model the near-wall phenomena as recommended [65]. The convergence of the simulation was monitored that until scaled residuals were less than $10^{-4}$ for continuity, less than $10^{-5}$ for momentum, turbulent kinetic energy and turbulent dissipation rate and less than $10^{-7}$ and for energy. The convergence was further monitored by ensuring that the volume averaged monitors for the absorber tube's wall temperature and volume averaged entropy generation rate ceased changing for more than 150 successive iterations.

The discretized computational grid used in this study is shown in Figs. 5(a) and 5(b). This is the general appearance of the mesh obtained after mesh dependence studies. A certain number of prism layers were included to ensure a $y^{+}$value lower than 1 in all simulations for the precise prediction of temperature and velocity fields, and accordingly the heat transfer and fluid friction performance. 


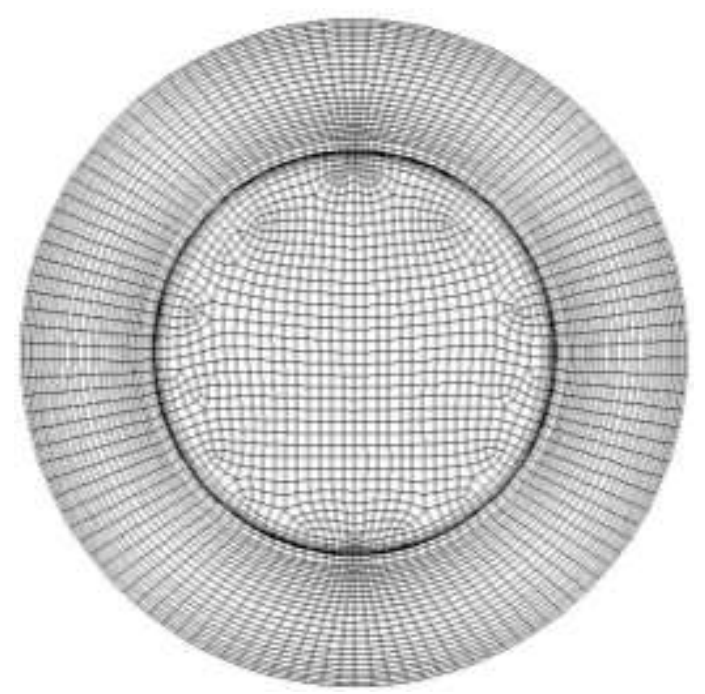

(a) Cross-section view of the mirrored receiver on the symmetry plane

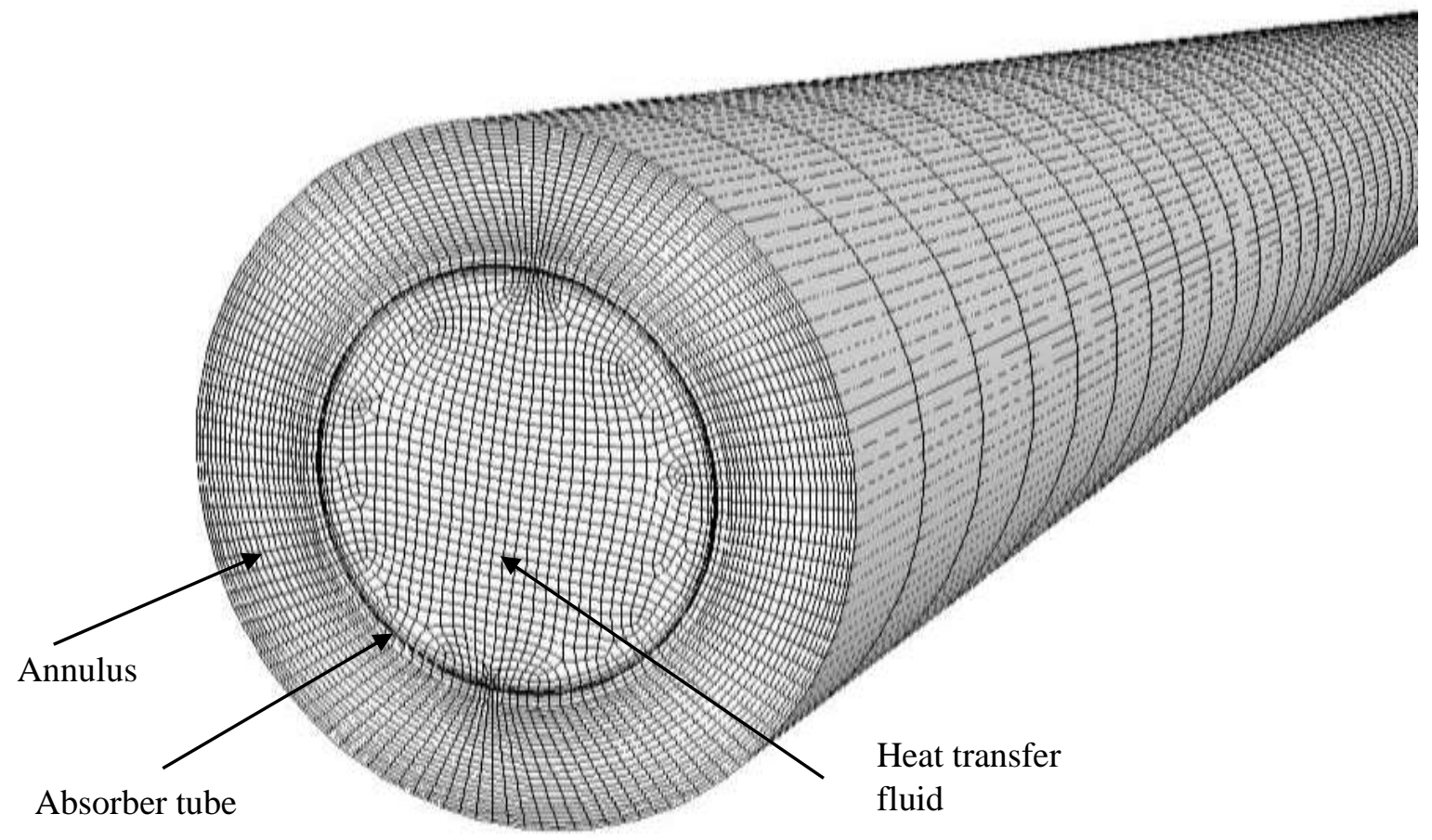

(b) Longitudinal view of the receiver's mesh (perspective view)

Fig. 5. Discretized computational domain of the receiver tube

Mesh independent studies were done for representative combinations of volume fraction, Reynolds number and inlet temperature. Both the Reynolds number and inlet temperature affect the mesh since $y^{+}$changes with the increase of Reynolds numbers and temperature. The thickness of the first prism layer was adjusted while either increasing the Reynolds number or the inlet 
temperature for the specified ranges in case of keeping one of these variables constant. The solution was accepted to be mesh independent when the changes in the thermal efficiency and the entropy generation rate were less than $1 \%$ as the mesh size reduced. Table 3 shows the sample mesh dependence studies at different inlet temperatures, volume fractions, and flow rates. In general, the number of mesh elements for the specified range of parameters were between 752,610 and 1,102,504 depending on the inlet temperature and Reynolds number.

Table 3. Sample mesh dependence studies for SWCNTs-Therminol®VP-1

\begin{tabular}{|c|c|c|c|c|}
\hline \multicolumn{5}{|c|}{$T_{\text {in }}=500 \mathrm{~K}, \phi=2 \%$ and $\dot{V}=20.41 \mathrm{~m}^{3} \mathrm{~h}^{-1}$} \\
\hline $\begin{array}{l}\text { Number } \\
\text { of elements }\end{array}$ & $\begin{array}{l}\text { Thermal efficiency, } \eta \\
(\%)\end{array}$ & $\begin{array}{l}\text { Entropy generation rate } \\
S_{\text {gen }}^{\prime} \\
\left(\mathrm{W} \mathrm{m}^{-1} \mathrm{~K}^{-1}\right)\end{array}$ & $\begin{array}{l}\text { Percentage change } \\
\text { in } \eta(\%)\end{array}$ & $\begin{array}{l}\text { Percentage } \\
\text { change in } \\
S_{g e n}^{\prime}(\%)\end{array}$ \\
\hline 452522 & 63.66 & 0.5783 & - & - \\
\hline 665353 & 65.90 & 0.5849 & 3.4 & 1.13 \\
\hline 825925 & 66.82 & 0.5864 & 1.4 & 0.26 \\
\hline 1148234 & 66.82 & 0.5866 & 0.0 & 0.03 \\
\hline \multicolumn{5}{|c|}{$T_{\text {in }}=600 \mathrm{~K}, \phi=0.5 \%$ and $\dot{V}=36.74 \mathrm{~m}^{3} \mathrm{~h}^{-1}$} \\
\hline 779453 & 58.40 & 0.28421 & - & - \\
\hline 956352 & 59.60 & 0.28258 & 2.0 & -0.58 \\
\hline 1346517 & 59.61 & 0.28256 & 0.02 & -0.007 \\
\hline
\end{tabular}

The last step in the procedure of the numerical solution was the determination of the entropy generation rates due to the heat transfer and fluid flow irreversibilities. These were determined by writing custom field functions representing Eqs. (15) - (17). Then, the entropy generation rates were obtained during the post processing stage of the computational fluid dynamics analysis.

\section{Results and discussion}

\subsection{Validation of the numerical model}

This study uses the same modeling approach used in the previous studies by Mwesigye et al. $[23,35,36,72]$. In these studies, the optical performance of the parabolic trough system [35,36], the entropy generation model [72], and the thermal performance of the receiver [23,36] were validated based on the data available in the literature, and good agreements were obtained for each item. The optical performance was compared with the results revealed by Jeter [73]. The thermal performance was validated by the widely used data from Sandia National Laboratories 
$[23,74]$ and heat loss data from Dreyer et al. [75]. It was shown in these studies that the developed optical, thermal performance and entropy generation models were in excellent agreement with data in the literature. Readers interested in the validation of these models are referred to the previous studies mentioned. The thermal conductivity model for nanofluids presented in this paper was compared with the results from Nan et al. [53] to ensure that the introduced user defined functions accurately portray the thermal conductivity of the resulting nanofluid. As shown in Fig. 6, the present study predicts the thermal conductivity ratio excellently within the error band lower than $\pm 1 \%$.

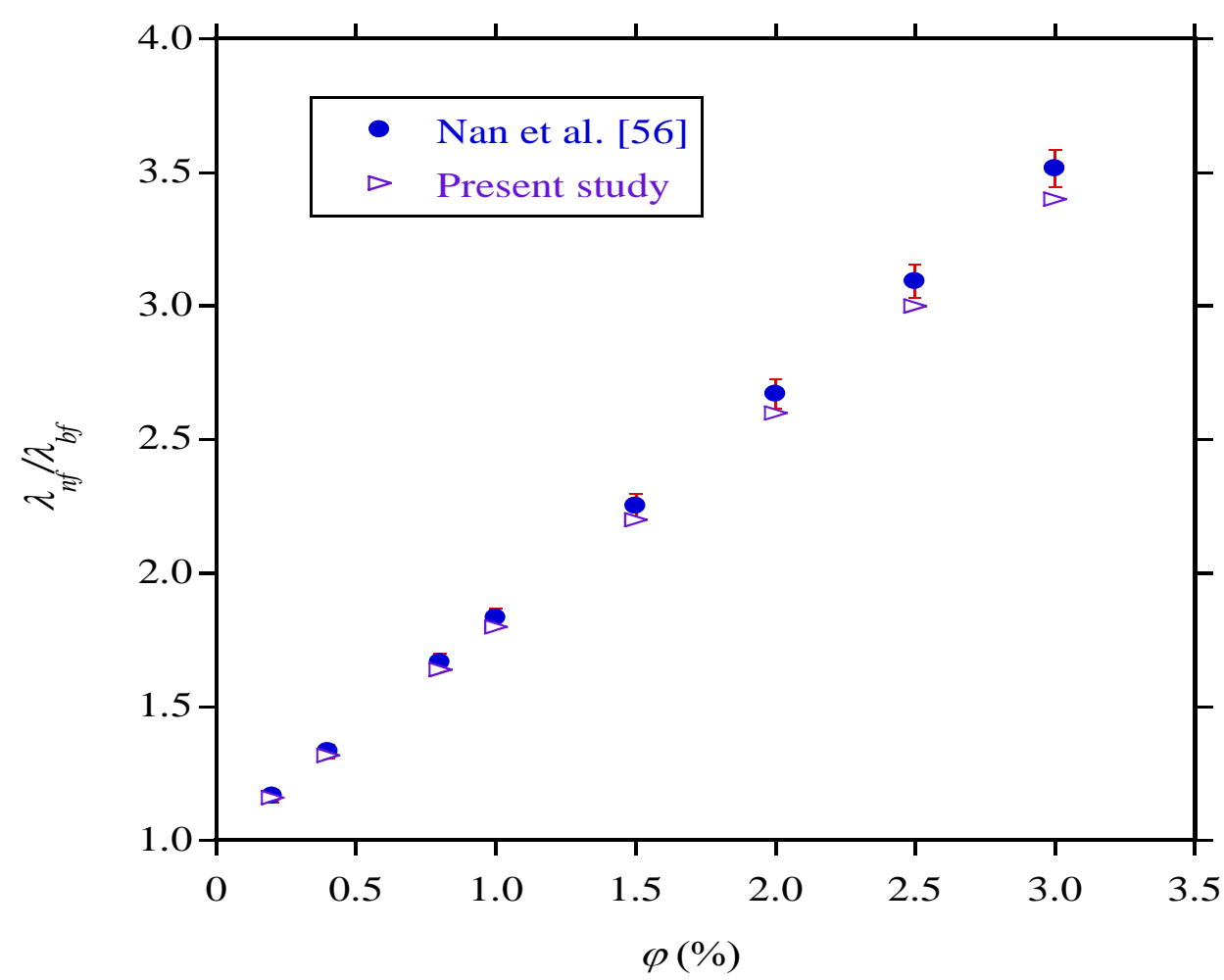

Fig. 6. Comparison of the thermal conductivity model to Nan et al. [53]

\subsection{Heat transfer performance}

As can be expected, the use of SWCNTs-Therminol@VP-1 nanofluid improve the convective heat transfer performance in the receiver's absorber tube owing to the higher thermal conductivity of the resulting nanofluid. Figure 7(a), shows the variation of the heat transfer coefficient on the absorber tube's inner wall with Reynolds number at different volume fractions for an inlet temperature of $500 \mathrm{~K}$. Clearly, higher heat transfer coefficients are obtained with the use of SWCNTs. The heat transfer performance increases almost linearly as the volume fraction 
and the Reynolds number increase. This is mainly due to the increased thermal conductivity of the resulting nanofluid with the suspension of SWCNTs. As seen in Fig. 6 and as was previously shown by Nan et al. [53], SWCNTs can give significantly higher thermal conductivity ratios, even at low volume fractions. The thermal conductivity of the nanofluid having $2 \%$ SWCNTs by volume is nearly 2.5 times higher than that of the base fluid. The heat transfer performance can increase by about $240 \%$ by use of SWCNTs-Therminol ${ }^{\circledR} V P-1$ nanofluid as the volume fraction increases from 0 to $2.5 \%$ for the associated range of Reynolds numbers.

Figure $7(\mathrm{~b})$ shows the variation of the heat transfer performance with Reynolds number at different volume fractions for an inlet temperature of $600 \mathrm{~K}$. A similar trend as in Fig. 7(a) exists but with higher heat transfer coefficients. This is because at higher temperatures, the HTF is less viscous and less dense and therefore can transport heat energy more effectively. This is also shown in the Reynolds number difference between Fig. 7(a) and Fig. 7(b), despite the fact that at all inlet temperatures, the flow rates are the same and in the range $1.63 \mathrm{~m}^{3} \mathrm{~h}^{-1}$ and $69.41 \mathrm{~m}^{3} \mathrm{~h}^{-1}$. In the figures with the Reynolds number on the $\mathrm{x}$-axis, each data point corresponds to the flow rates $1.63,4.08,12.25,20.41,28.58,36.75,44.91,53.08,61.24$ and 69.41 , respectively irrespective of the inlet temperature.

To explicitly show the influence of operating temperature on the heat transfer performance, the variations with the inlet temperature were considered under specified volume fractions. Here, the heat transfer performance was indicated as a measure of the change in the convection heat transfer coefficient in the absorber tube. As shown in Fig. 8(a), the heat transfer performance is higher for higher inlet temperatures at the same flow rates. The same flow rates as was used for Fig.7 were considered. Although the heat transfer performance seems to be lower at high inlet temperatures, in fact; it is not since the thermal properties of the HTF vary with temperatures, and the Reynolds number will be higher at high values of temperatures under the same flow rate. For example, at a flow rate of $28.58 \mathrm{~m}^{3} \mathrm{~h}^{-1}$, the Reynolds numbers are obtained to be 133111 , $181708,226123,270065$ for the inlet temperatures of $450 \mathrm{~K}, 500 \mathrm{~K}, 550 \mathrm{~K}$ and $600 \mathrm{~K}$, respectively. Thus, higher flow rates would be required at low inlet temperatures to have the same Reynolds number as compared with higher inlet temperatures. 


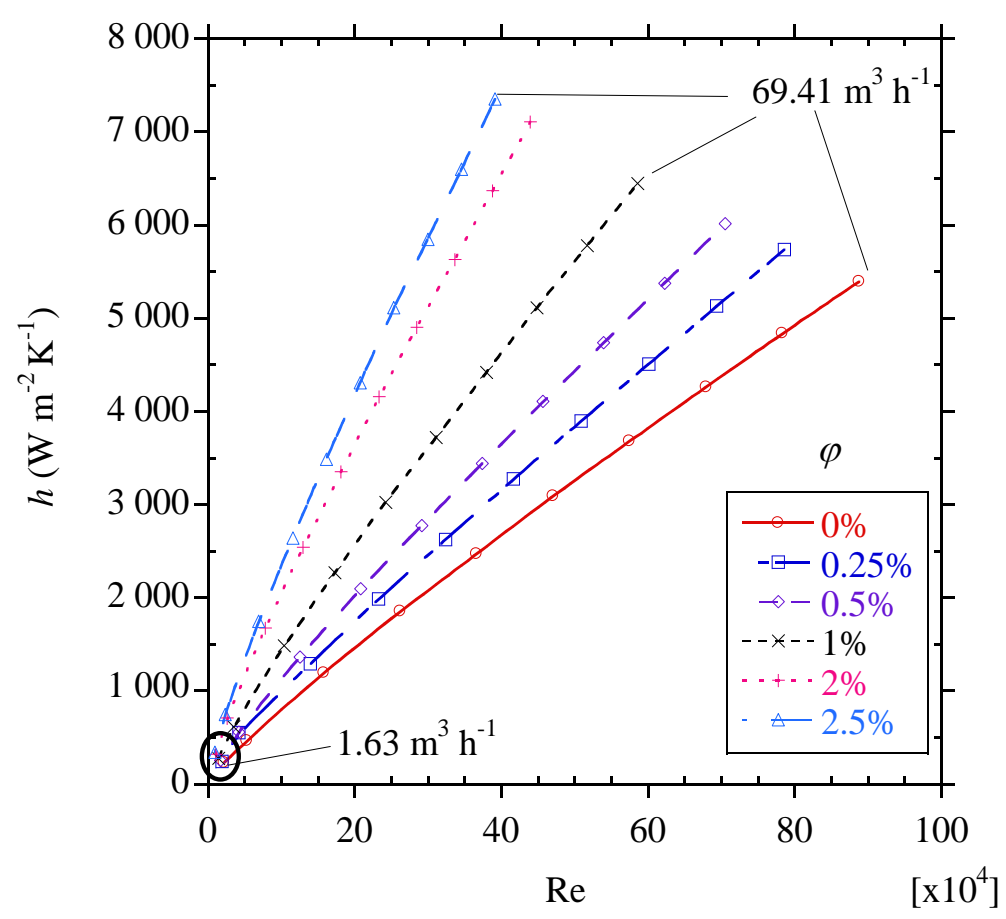

(a)

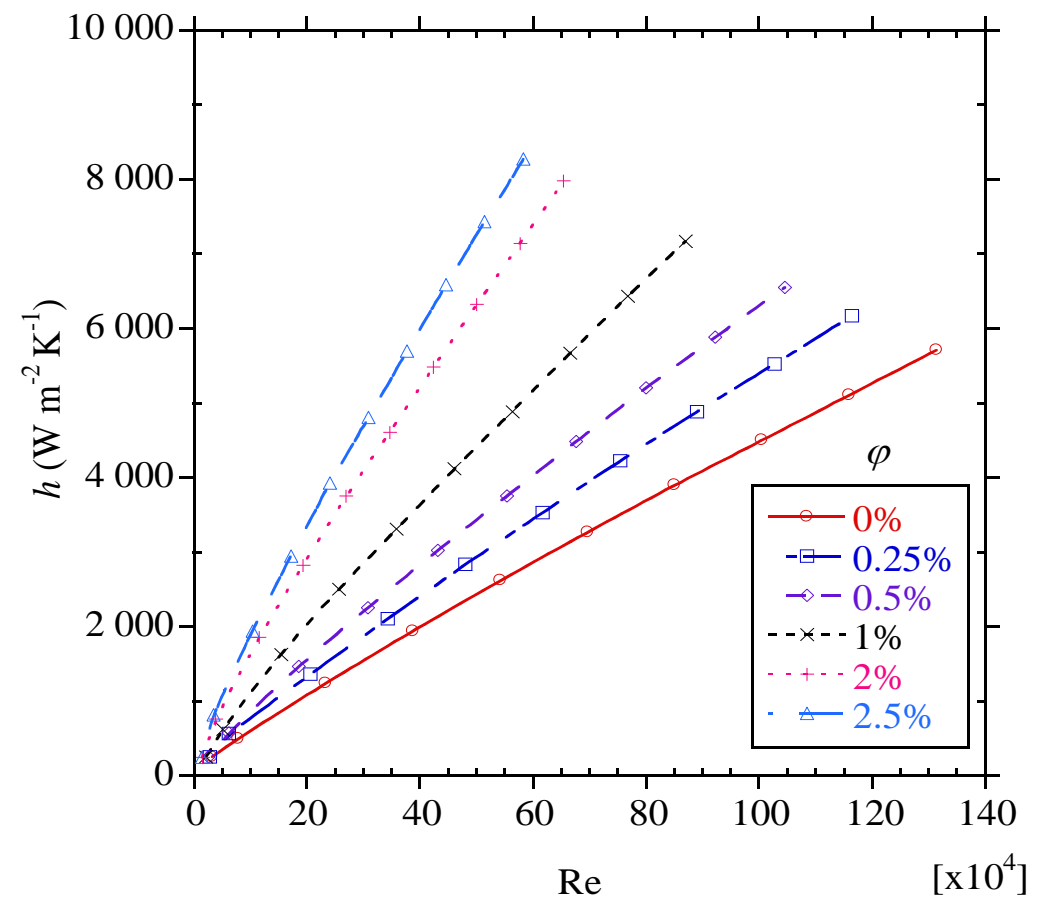

(b)

Fig. 7. Heat transfer performance as a function of Reynolds number and volume fraction (a) at $T_{\text {in }}=500 \mathrm{~K}$ and (b) at $T_{\text {in }}=600 \mathrm{~K}$

To dispel this possible confusion, the heat transfer performance was plotted with respect to flow rate which does not consider the effects of HTF density and viscosity. As shown in Fig. 8(b), the 
heat transfer performance increases with inlet temperature under the specified conditions. Generally, the heat transfer performance will improve as the HTF is heated along the length of the receiver's absorber tube. This is mainly due to the reduction in both fluid density and viscosity with temperature increment.

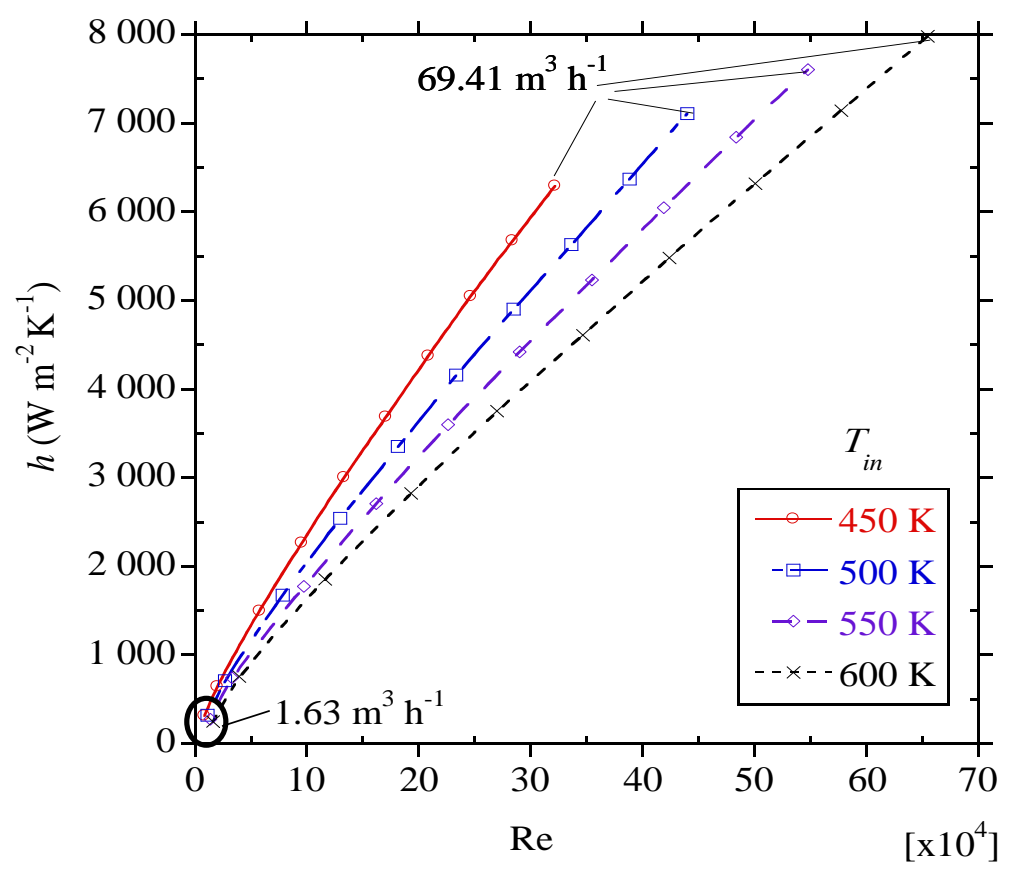

(a)

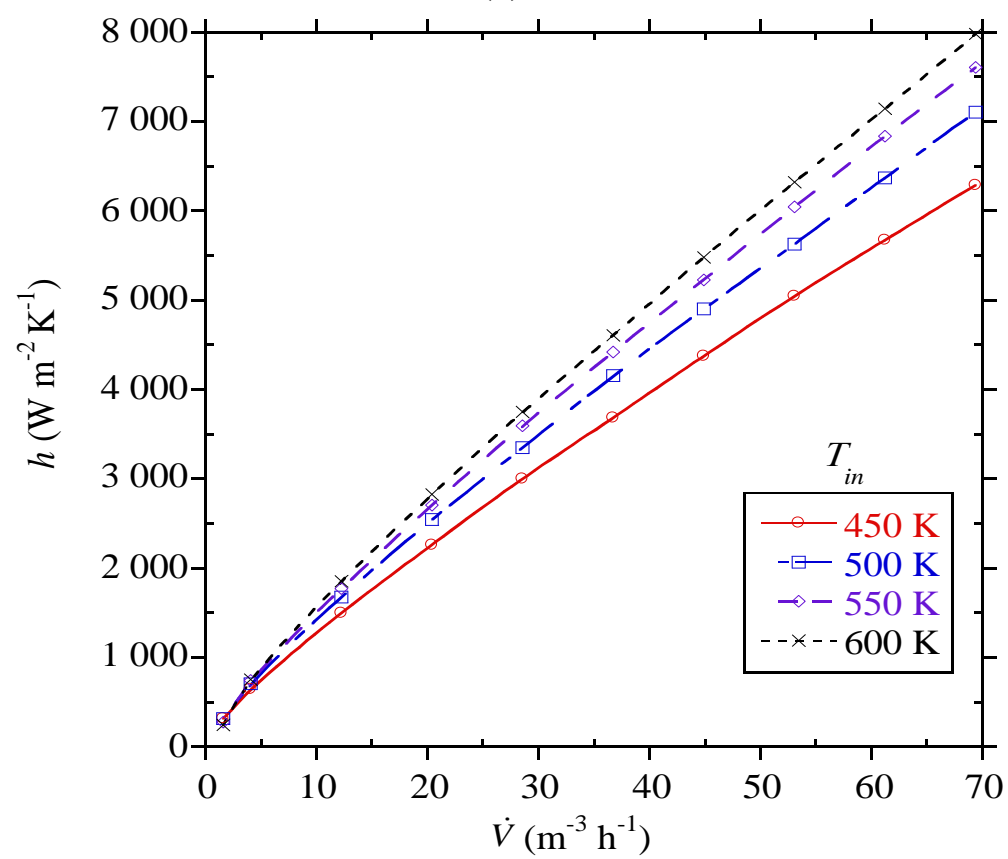

(b)

Fig. 8. Heat transfer performance based on (a) Reynolds number at different inlet temperatures and $\varphi=2 \%$ (b) volumetric flow rate at different inlet temperatures and $\varphi=1 \%$ 


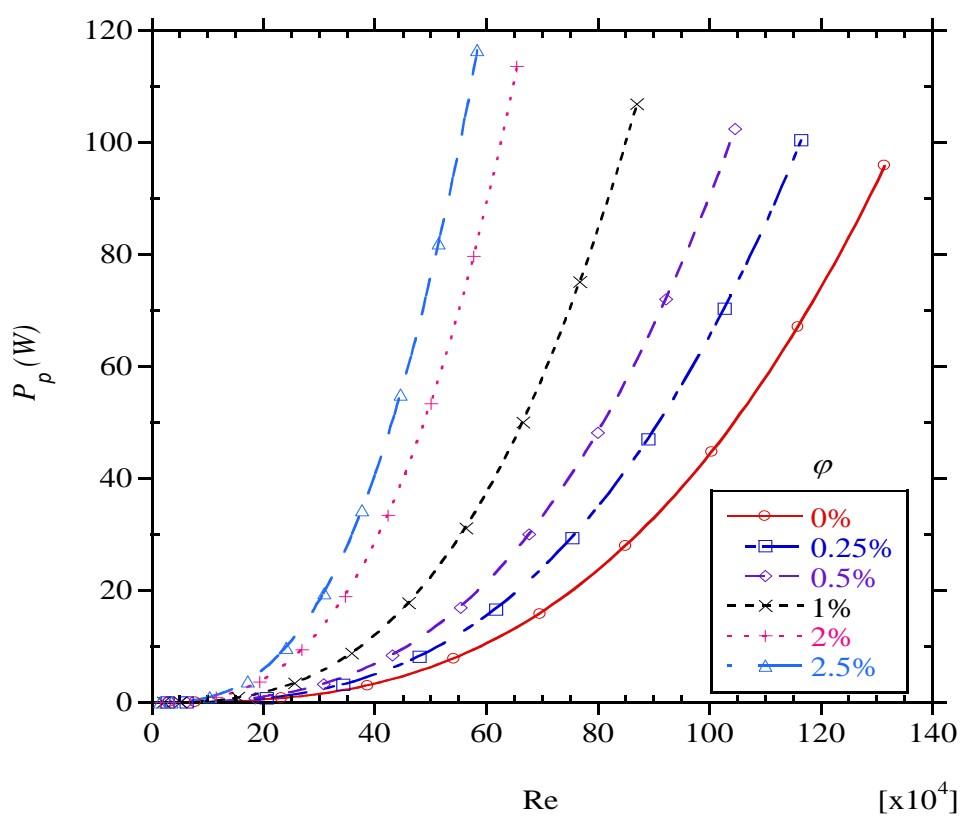

(a)

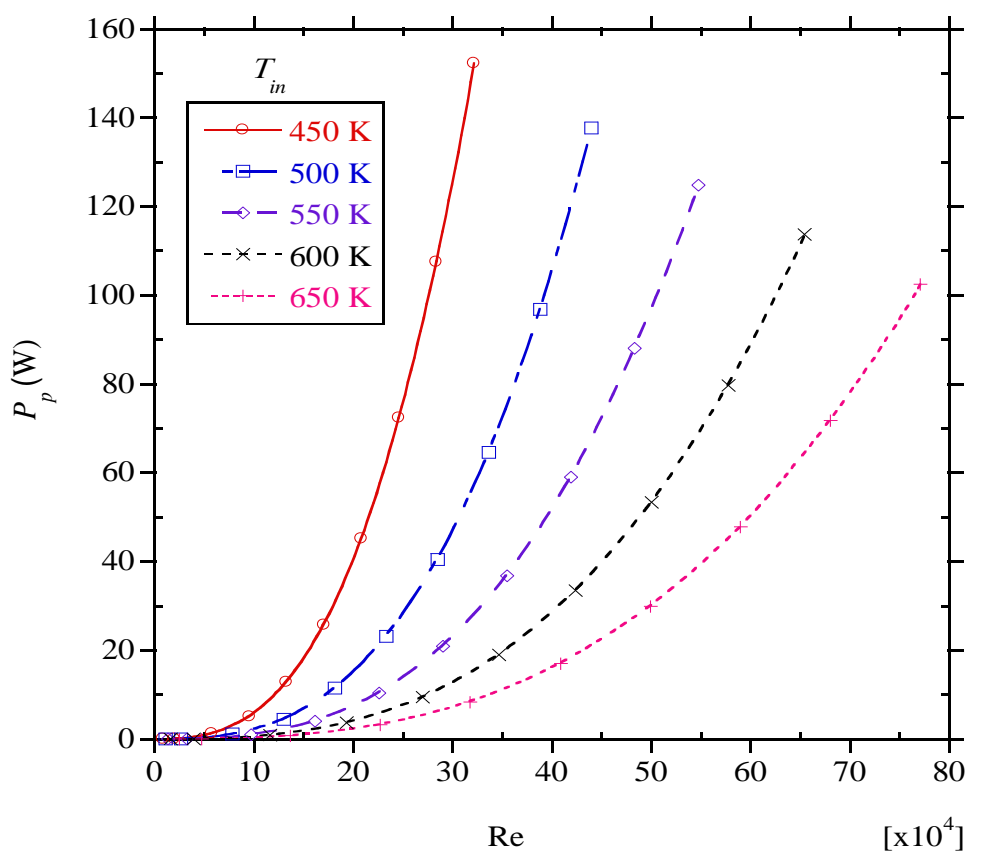

(b)

Fig. 9. Variation of pumping power as a function of (a) Reynolds number and volume fraction at $T_{i n}=600 \mathrm{~K}$, and (b) Reynolds number and inlet temperature at $\varphi=2 \%$

\subsection{Pumping power}

With the inclusion of nanotubes in the HTF, the fluid friction is expected to increase due to the increased density and viscosity of the resulting nanofluid. Noting that using nanotubes instead of spherical nanoparticles results in higher fluid friction due to their geometrical shape. Figure 9(a) 
depicts the variation of pumping power with Reynolds number at different nanotube volume fractions for the inlet temperature of $600 \mathrm{~K}$. As expected the pumping power increases with increasing Reynolds number and nanotube volume fraction. However, significant increments in pumping power are shown to exist for the Reynolds numbers corresponding to flow rates higher than $36.74 \mathrm{~m}^{3} \mathrm{~h}^{-1}$. Lower than this flow rate, the pumping power does not increase significantly as the volume fraction increases. Moreover, most commercial parabolic trough CSP plants operate with flow rates around this value depending on the incident solar radiation $[63,74]$. Thus, there is potential to achieve significant heat transfer performance with lesser pumping power requirement for practical PTSC systems, even with lower volume fractions as considered in this study. As shown in Fig. 9(b), the pumping power is shown to be higher at lower inlet temperatures at a given Reynolds number. This is true both at considerable flow rates and considerable Reynolds numbers. This phenomenon is expected since at lower temperatures the HTF is denser and more viscous requiring significant amounts of power to move through the absorber tube.

\subsection{Thermal efficiency}

The thermal efficiency of the PTSC considers the increase in performance due to improved heat transfer at the expense of thermal losses and the pumping power as Eq. (14) indicates. The variation of the thermal efficiency with Reynolds number and volume fraction is presented in Fig. 10(a). As clearly shown, the thermal efficiency increases up to a certain value and reaches its maximum value and then starts to decrease, even becoming lower than that of the case without nanofluid at higher Reynolds numbers and volume fractions. At low flow rates, there is increased heat transfer performance and lower pumping power requirements leading to increased thermal efficiency with the increase of Reynolds number. Further increase in the flow rate will increase the heat transfer performance as already shown, but the pumping power required becomes significantly higher than the useful heat gain. In this case, the improvement in the heat transfer performance will not compensate the increased pumping power thus lower thermal efficiency is obtained. The other contribution to the increase in thermal performance is the reduction in absorber tube temperature with heat transfer enhancement and accordingly the reduction of receiver thermal losses as was shown in earlier studies [22,34].

It is interesting to note that although the enhancement in heat transfer performance using SWCNT nanofluid is relatively high compared to the base fluid, the improvement in the thermal 
efficiency is unfortunately not at the same degree. The thermal efficiency is shown to increase by about $4.4 \%$. Much higher values such as $12.5 \%$ and $13.9 \%$ for copper and silver nanoparticles respectively we obtained in earlier studies $[13,23]$. This is the evidence of the fact that the thermal conductivity is not the unique property to improve the performance of a solar thermal energy system using nanofluids. The present study shows that the higher specific heat capacity of SWCNTs about $1800 \mathrm{~J} \mathrm{~kg}^{-1} \mathrm{~K}^{-1}$ compared to that of copper and silver about $396-421 \mathrm{~J} \mathrm{~kg}^{-1} \mathrm{~K}^{-1}$ and 238-252 $\mathrm{J} \mathrm{kg}^{-1} \mathrm{~K}$, respectively are the potential cause of having lower thermal efficiency improvement. This means that the resulting SWCNTs-Therminol®VP-1 nanofluid would require significantly more energy for the differential temperature rise and thus lower actual energy output as compared to copper and silver - Therminol ${ }^{\circledR V P}-1$ nanofluids. This result is also in line with the results of Alashkar and Gadalla [42], who showed that the use of SWCNTs in a PTSC integrated solar regenerative Rankine cycle yielded the lowest annual energy output as compared with copper and silver. Therefore, for thermal energy generating systems, the influence of both thermal conductivity and specific heat capacity needs to be assessed to decide whether the use of nanofluids improves the thermal performance.

As shown in Fig. 10(a), the increase in efficiency is higher for low Reynolds numbers or flow rates. There will be significant improvements provided that the flow rates are lower than 28.6 $\mathrm{m}^{-3} \mathrm{~h}^{-1}$ for all the inlet temperatures and the considered geometrical parameters.

The variation in the thermal efficiency based on the inlet temperature for a given volume fraction is shown in Fig. 10(b). It is relatively higher at low inlet temperatures because of the low absorber tube temperature and thus low receiver thermal loss [76]. Increasing the inlet temperature means higher absorber temperature, which causes increased receiver thermal losses, mainly due to radiation from the high temperature absorber tube to the low temperature surroundings. Moreover, since the HTF is denser and more viscous at low temperatures, the thermal efficiency increases to a maximum value and then begins to fall due to the increased pumping power with increased Reynolds numbers. At high temperatures, the reduction in the thermal efficiency with growing Reynolds number is not pronounced since the HTF is less dense and less viscous and therefore does not require significant amounts of pumping power as was already discussed. 


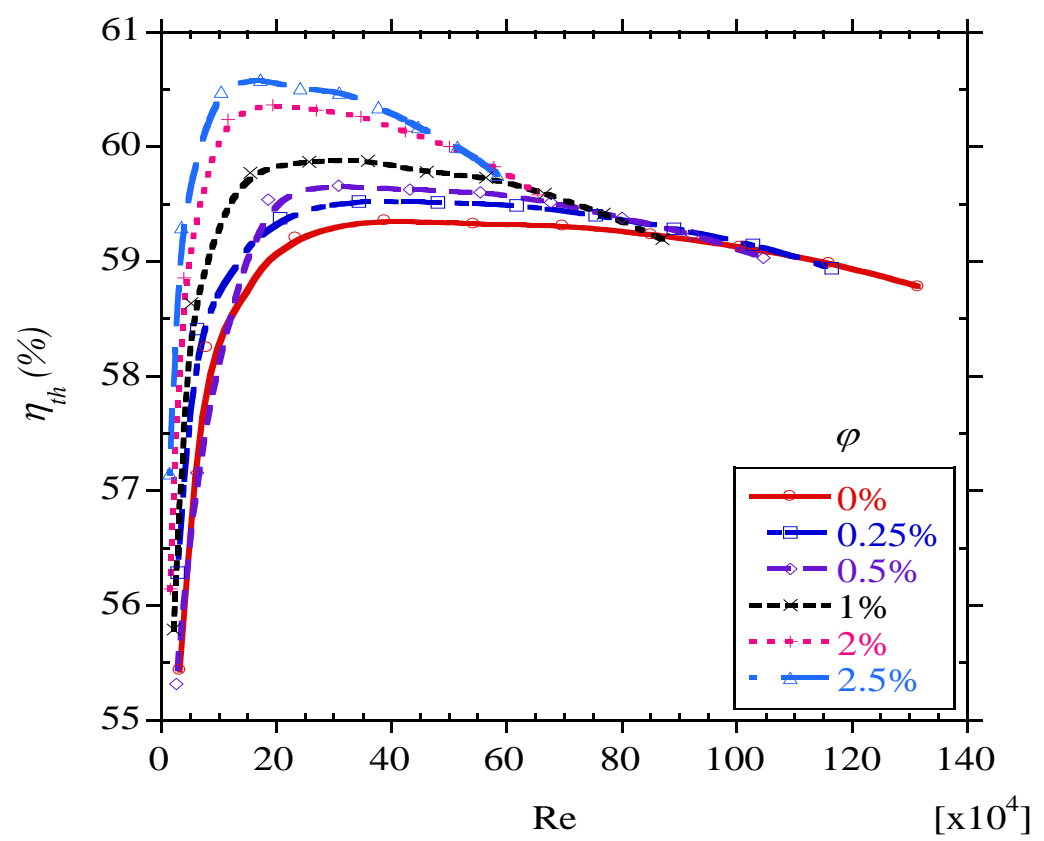

(a)

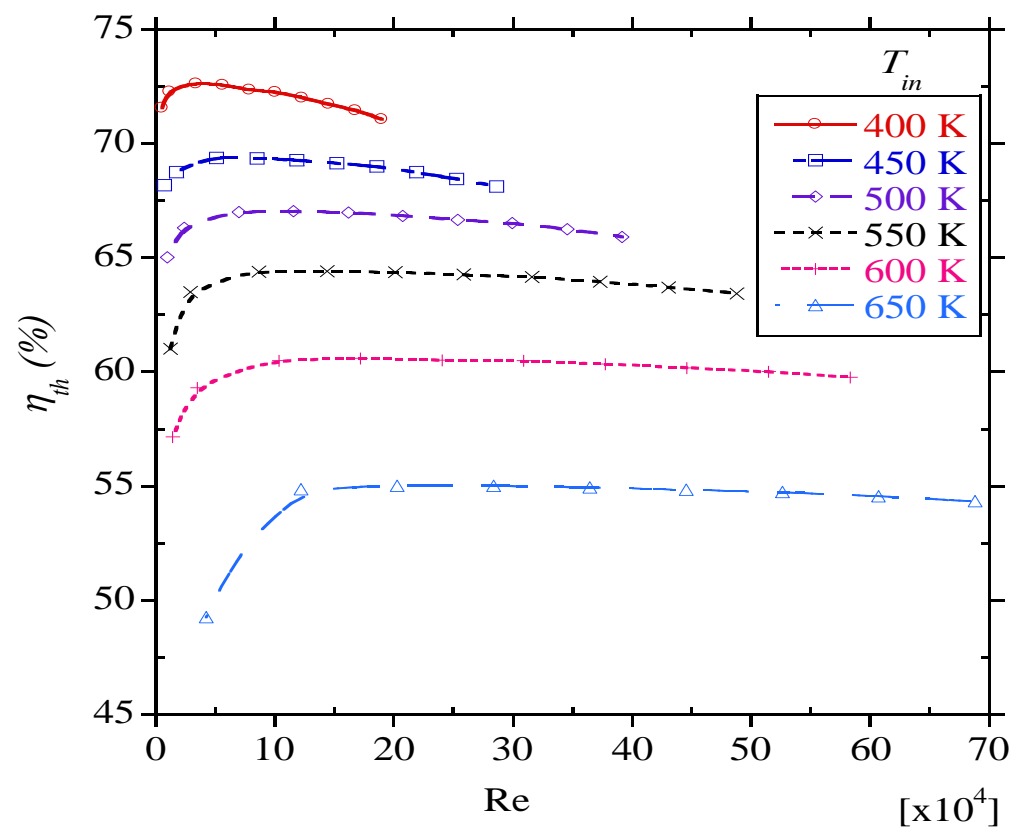

(b)

Fig. 10. Variation of thermal efficiency as a function of (a) Reynolds number and volume fraction at $T_{i n}=600 \mathrm{~K}$, and (b) Reynolds number and inlet temperature at $\varphi=2.5 \%$.

Despite having low improvement in the thermal efficiency, using SWCNTs-Therminol ${ }^{\circledR V P}-1$ nanofluid leads to an appreciably higher reduction in the temperature gradients of the absorber tube. Higher receiver tube temperature gradients have been shown to be the primary cause of the receivers' failure in PTSC systems. Hence, reducing the temperature gradient over the receiver will reduce the thermal stresses and consequently increase its reliability. At $4.08 \mathrm{~m}^{3} \mathrm{~h}^{-1}$, the 
maximum circumferential temperature gradient decreases from $167 \mathrm{~K}$ to $108 \mathrm{~K}$, i.e., a $35.3 \%$ drop, as the volume fraction increases from 0 to $2.5 \%$. At $20.4 \mathrm{~m}^{3} \mathrm{~h}^{-1}$, the drop is $24.8 \%$ for the associated condition. As such, higher reduction in the absorber tube temperature is expected at relatively low flow rates. Figure 11 (a) and (b) depicts the temperature contours at $4.08 \mathrm{~m}^{3} \mathrm{~h}^{-1}$ for an inlet temperature of $400 \mathrm{~K}$ and volume fractions of $0 \%$ and $2.5 \%$, respectively. The reduction in absorber tube temperature gradients at $2.5 \%$ volume fraction is clearly seen from the figure.

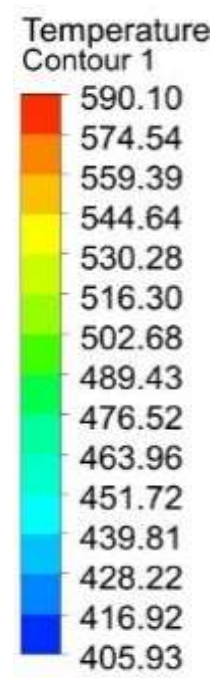

$[\mathrm{K}]$

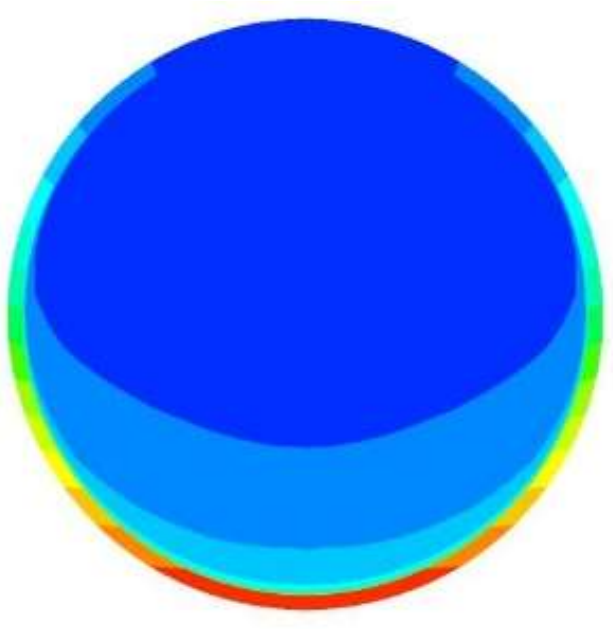

(a)

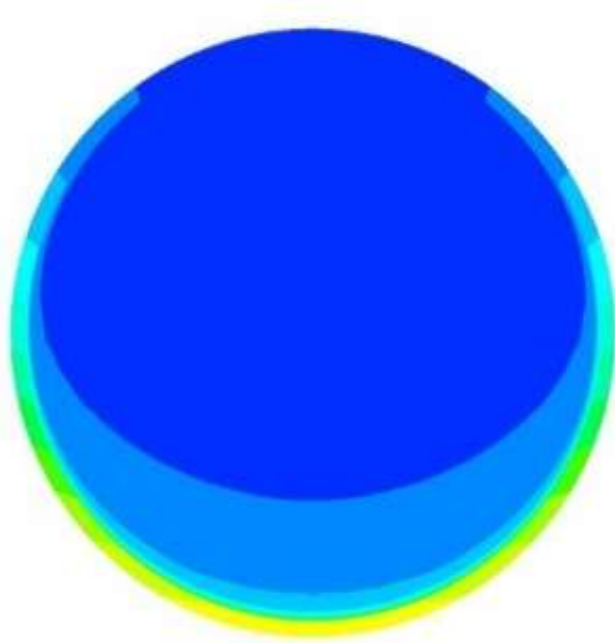

(b)

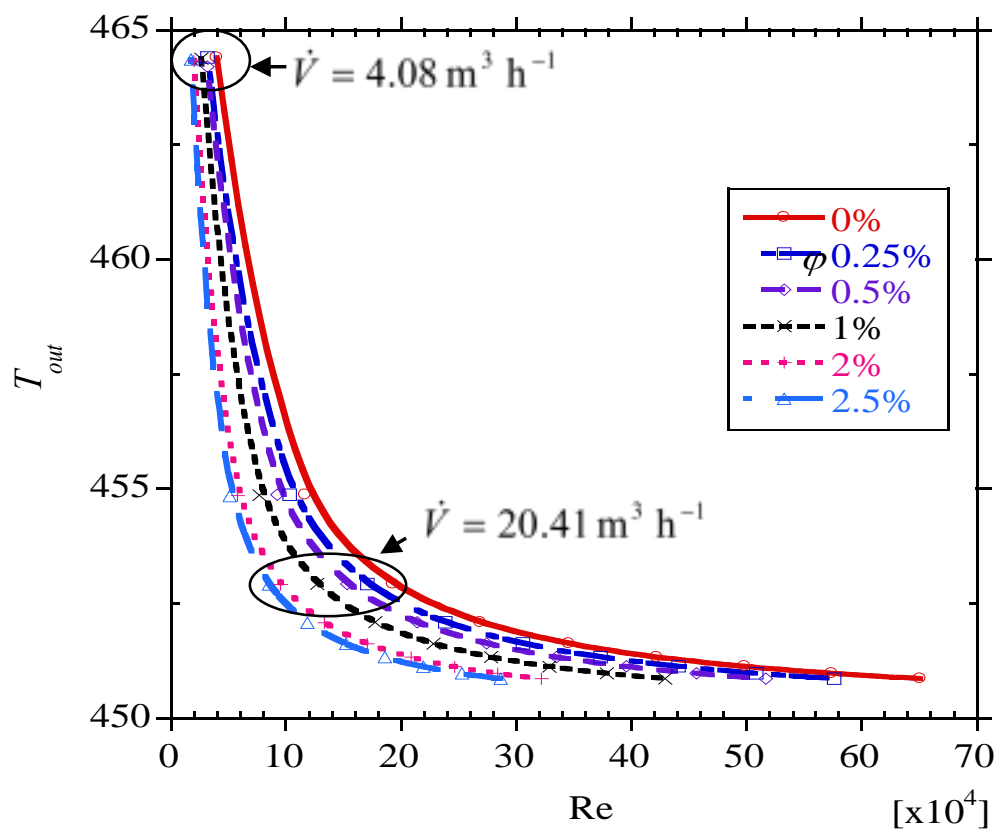


(c)

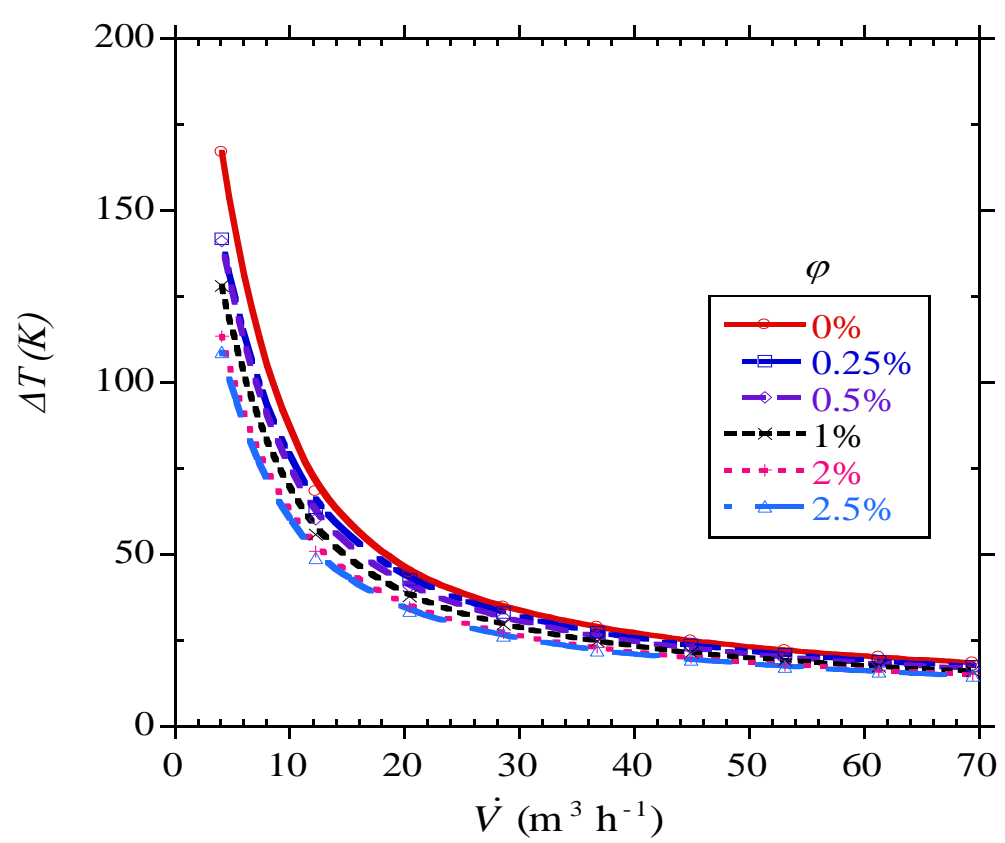

(d)

Fig. 11. Contours of the absorber tube's outlet temperature at $T_{\text {in }}=400 \mathrm{~K}$ and a flow rate of $4.08 \mathrm{~m}^{3} \mathrm{~h}^{-1}$ (a) $\varphi=0 \%$, (b) $\varphi=2.5 \%$, (c) Variation of bulk temperature at the absorber tube outlet with Reynolds number and volume fraction at $T_{i n}=450 \mathrm{~K}$, and (d) absorber tube temperatrue gradients as a function of flow rate and volume fraction at $T_{\text {in }}=550 \mathrm{~K}$

Figure 11 (c) depicts the variation of the bulk fluid temperature at the absorber tube's outlet. As shown, the bulk fluid temperature does not change appreciably with volume fraction at a given flow rate. As was previously discussed, the high specific heat capacity of the resulting nanofluid means that more energy would be required to increase the fluid temperature compared to what would be needed only with the base fluid. It therefore appears that the improvement in the performance is mainly from the increased convective heat transfer performance, reduced thermal losses owing to the reduced absorber tube temperatures and increased heat capacity of the nanofluid. The absorber tube temperature gradient, $\Delta T$, defined as the maximum absorber tube temperature minus the minimum absorber tube temperature shows the reduction in temperature gradients as volume fractions increase as depicted in Fig. 11 (d). As an example, the temperature gradients reduce by $28 \%$ and $24 \%$ as the volume fraction increases from 0 to $2.5 \%$ at flow rates 
of $12.25 \mathrm{~m}^{3} \mathrm{~h}^{-1}$ and $28.58 \mathrm{~m}^{3} \mathrm{~h}^{-1}$, respectively. Significant reductions in absorber tube temperature gradients are shown to exist at low flow rates.

\subsection{Entropy generation and exergetic performance}

\subsubsection{Entropy generation analysis}

The determination of entropy generation rates in thermal systems and the minimization of these irreversibilities is an effective way of improving the thermodynamic performance of these systems [77]. For convective heat transfer, the main irreversibilities are the heat transfer and fluid flow irreversibilities. In this study, these two irreversibilities were obtained using Eq. (15) and (16). The total entropy generation rate is the sum of the heat transfer and fluid flow irreversibilities given by Eq. (17) for the entire control volume. Figure 12(a) illustrates the variation of the irreversibilities at volume fractions of $0.5 \%$ and $2.5 \%$, respectively for $450 \mathrm{~K}$ inlet temperature. As shown, the heat transfer irrversibilities are dominant at low Reynolds numbers owing to the high finite temperature differences in the receiver tube. The heat transfer irreversibility decreases with Reynolds number as the finite temperature difference reduces. However, the fluid flow irreversibilities are very small at low Reynolds numbers and increases with Reynolds number due to increased fluid friction. At much higher Reynolds numbers, the fluid flow irreversibility will increase and become the dominant source of irreversibility [36,72]. The total entropy generation rate is almost the same as the heat transfer irreversibility for the range of parameters considered. Thus, for this range of parameters, heat transfer enhancement is expected to reduce the finite temperature difference and thus the entropy generation rate. As Fig. 12(a) shows, the entropy generation rates at a volume fraction of $2.5 \%$ are much lower than those at the volume fraction of $0.5 \%$. The decrease in entropy generation rates with increasing Reynolds number and volume fraction is further demonstrated in Fig. 12(b) for the inlet temperature of $500 \mathrm{~K}$. The same trends were obtained at other inlet temperatures. 


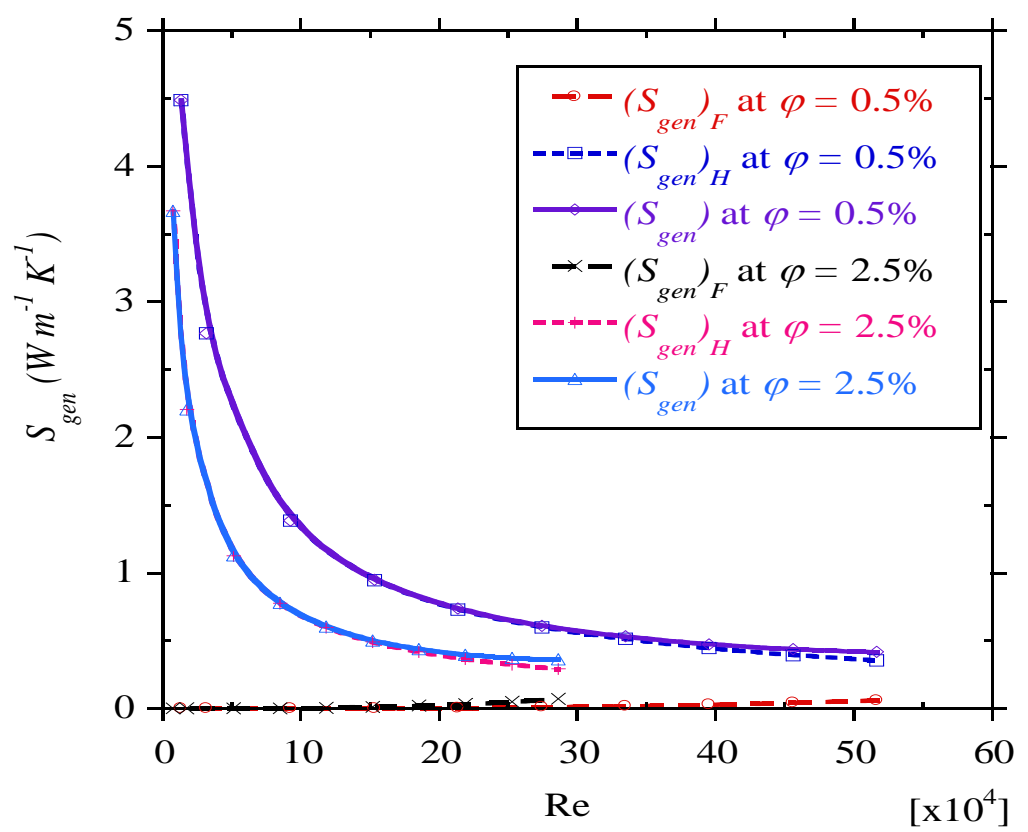

(a)

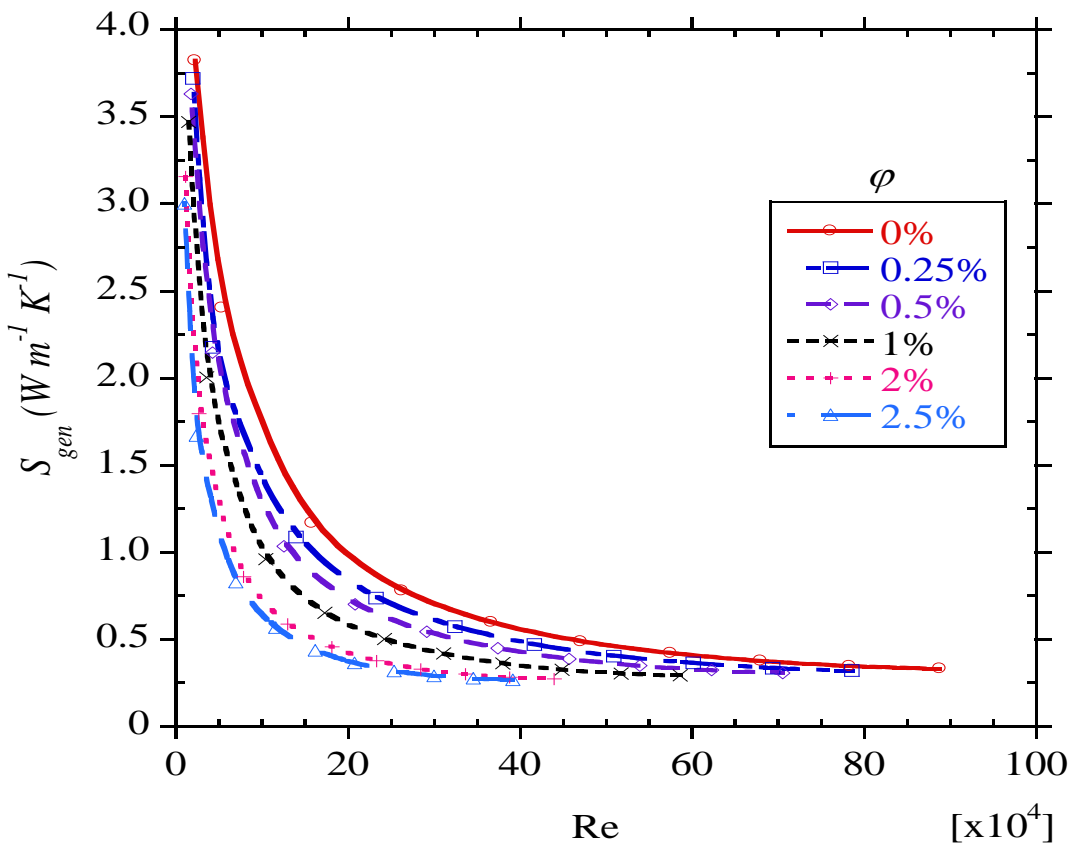

(b)

Fig. 12. Entropy generation rates as a function of (a) Reynolds number when $T_{i n}=450 \mathrm{~K}$ at $\varphi=0.5 \%$ and $2.5 \%$, and (b) Reynolds number and volume fraction for $T_{i n}=500 \mathrm{~K}$.

The entropy generation rates are reduced by about $70 \%$ as the volume fraction increases from 0 to $2.5 \%$. This is expected since the heat transfer performance was much higher and thus significantly reduced finite temperature differences. Significant reductions in the entropy generation rates are achievable at flow rates lower than $36.7 \mathrm{~m}^{3} \mathrm{~h}^{-1}$. Higher entropy generation rates are expected at low inlet temperatures as shown in Fig. 13(a) and 13(b). At low inlet 
temperatures, the heat transfer performance is low due to increased heat transfer irreversibilities, and the fluid friction is higher due to the high density and viscosity HTF. As the temperatures increase, the change in the properties of the HTF leads to improved heat transfer performance and also makes the fluid less dense and less viscous, thus less fluid friction irreversibilities.

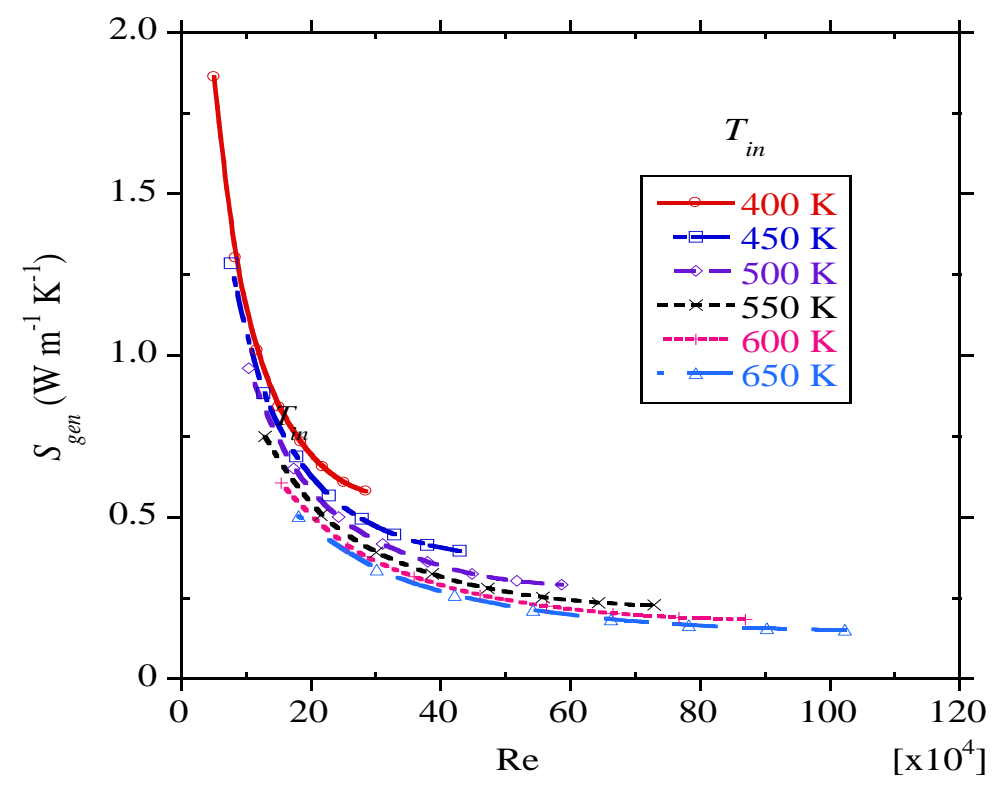

(a)

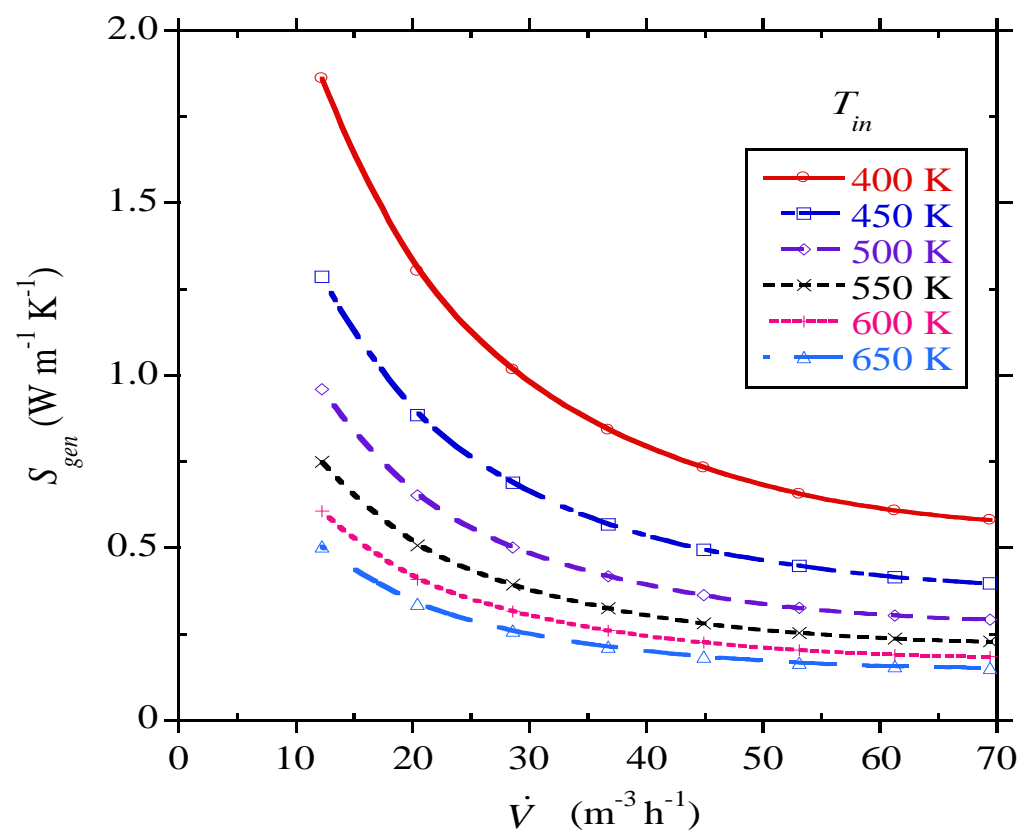

(b)

Fig. 13. Entropy generation at different inlet temperatures as a function of (a) Reynolds number for $\varphi=1 \%$ and (b) volume flow rate for $\varphi=1 \%$ 
The contribution of each irreversibility to the total entropy generation rate is presented using the Bejan number which represents the ratio of the entropy generation due to the heat transfer irreversibility to the total entropy generation rate. The Bejan number significantly reduces with increasing volume fraction at a given Reynolds number and with increasing Reynolds number at a given volume fraction as shown in Fig. 14(a). This is due to the reduced heat transfer irreversibility as the Reynolds number and volume fraction increase. The reduction in the Bejan number will also be partly due to increasing fluid friction as Reynolds number and volume fraction increase.

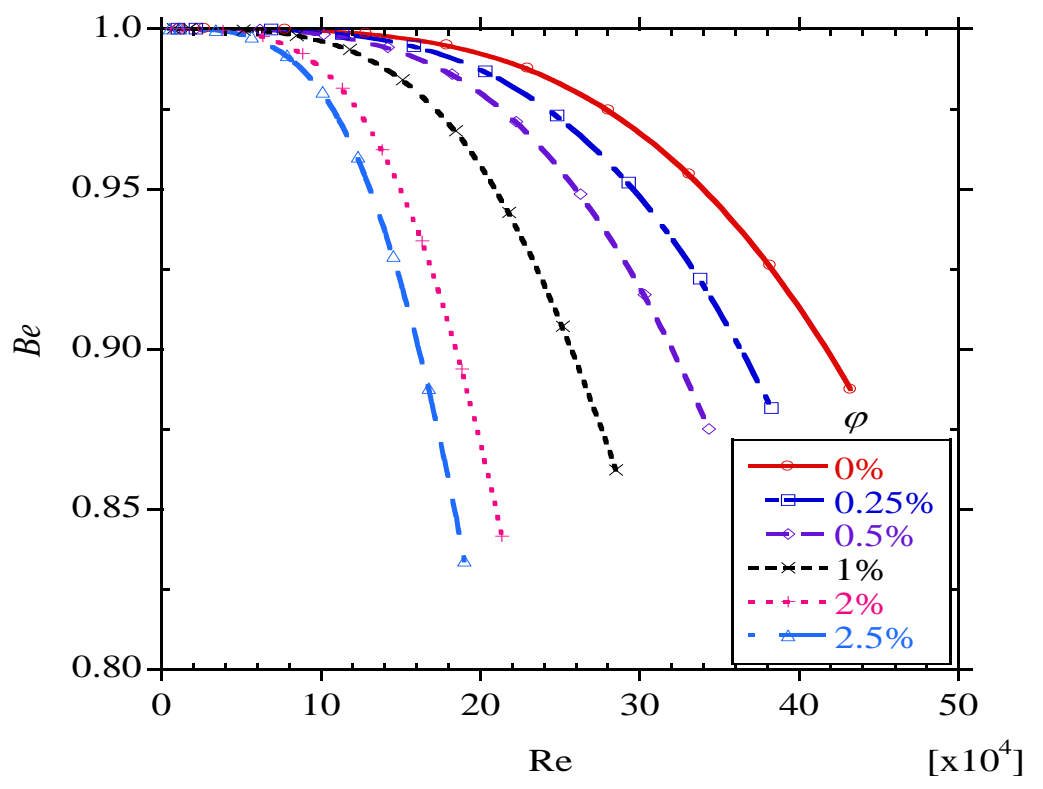

(a)

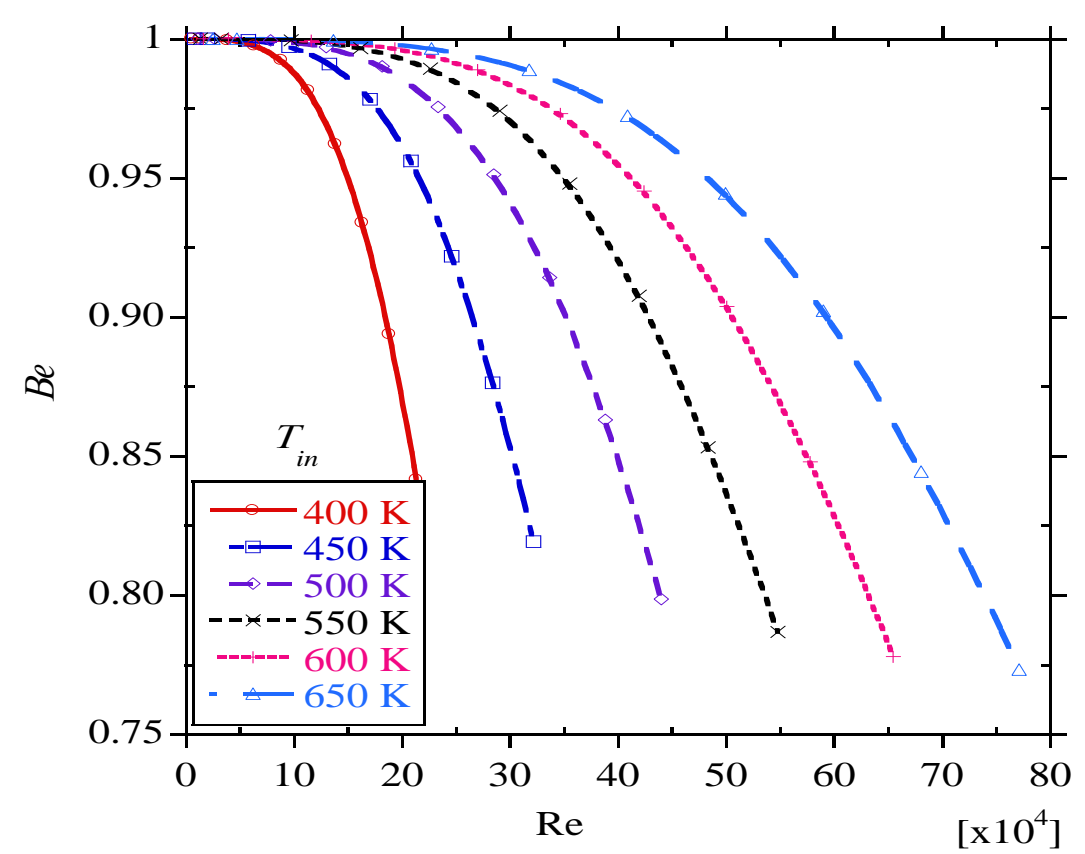


(b)

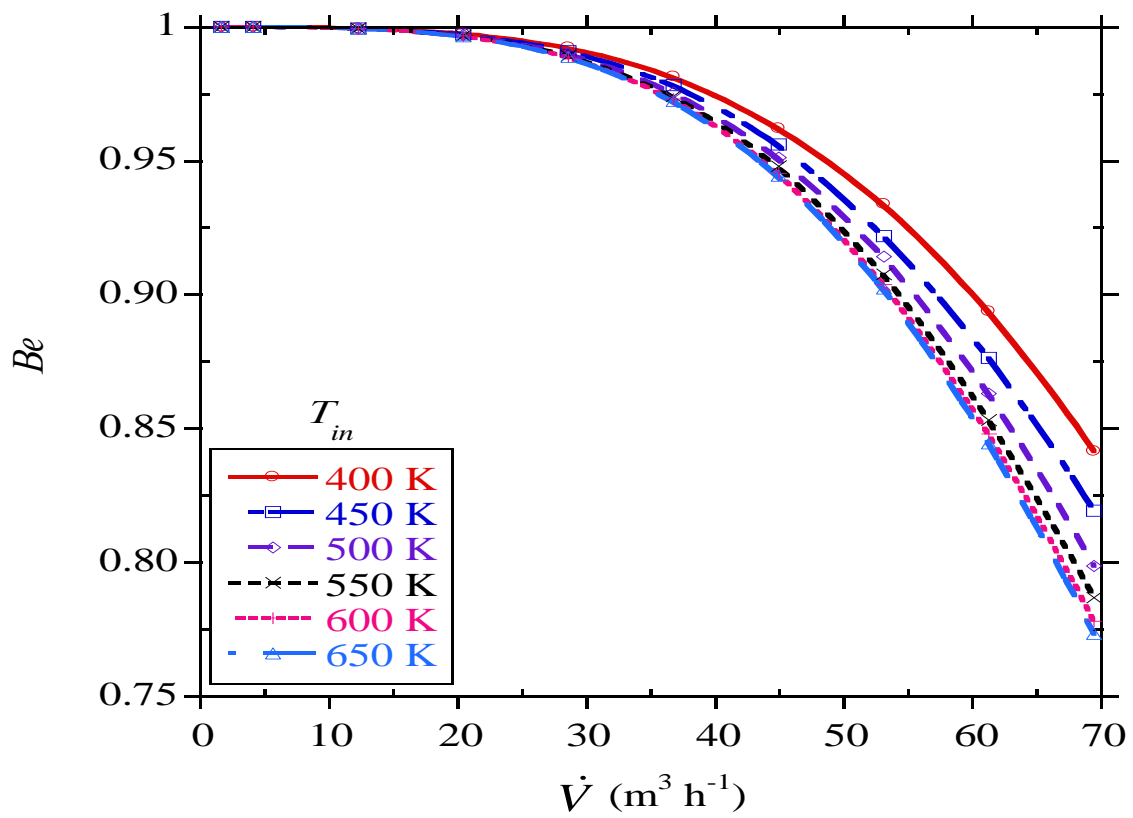

(c)

Fig. 14. Variation of the Bejan number as a function of (a) Reynolds number and volume fraction for $T_{\text {in }}=400 \mathrm{~K}$ (b) Reynolds number and inlet temperature for $\varphi=2 \%$ (c) flow rate and inlet temperature at $\varphi=2 \%$

At a given flow rate, lower inlet temperatures are shown to have higher Bejan numbers as shown in Fig. 14(a)-(c). This is expected since the heat transfer irreversibility will be higher when the finite temperature difference is higher due to poor heat transfer performance at low temperatures. However, at a given Reynolds number, the Bejan number is seen to be higher for higher inlet temperatures due to higher finite temperature differences and lower flow rates needed to achieve this Reynolds number compared to those at low temperatures. Moreover, at lower inlet temperatures, the fluid flow irreversibility associated with the higher fluid friction further reduces the Bejan number.

\subsubsection{Exergetic performance}

As a measure of exergetic performance, the exergy efficiency was evaluated using Eq. (21). The total entropy generation rate due to heat transfer and fluid flow irreversibilities has been used to determine the exergy destroyed given by Eq. (18). Fig. 15(a) represents the exergetic efficiency at different volume fractions as a function of the Reynolds number for the inlet temperature of $550 \mathrm{~K}$. As shown, the influence of the volume fraction on the exergetic efficiency is poor. The exergetic efficiency increases by about $1.3 \%$ for the range of parameters considered as the volume fraction increases from 0 to $2.5 \%$. The variation of the exergetic efficiency depends 


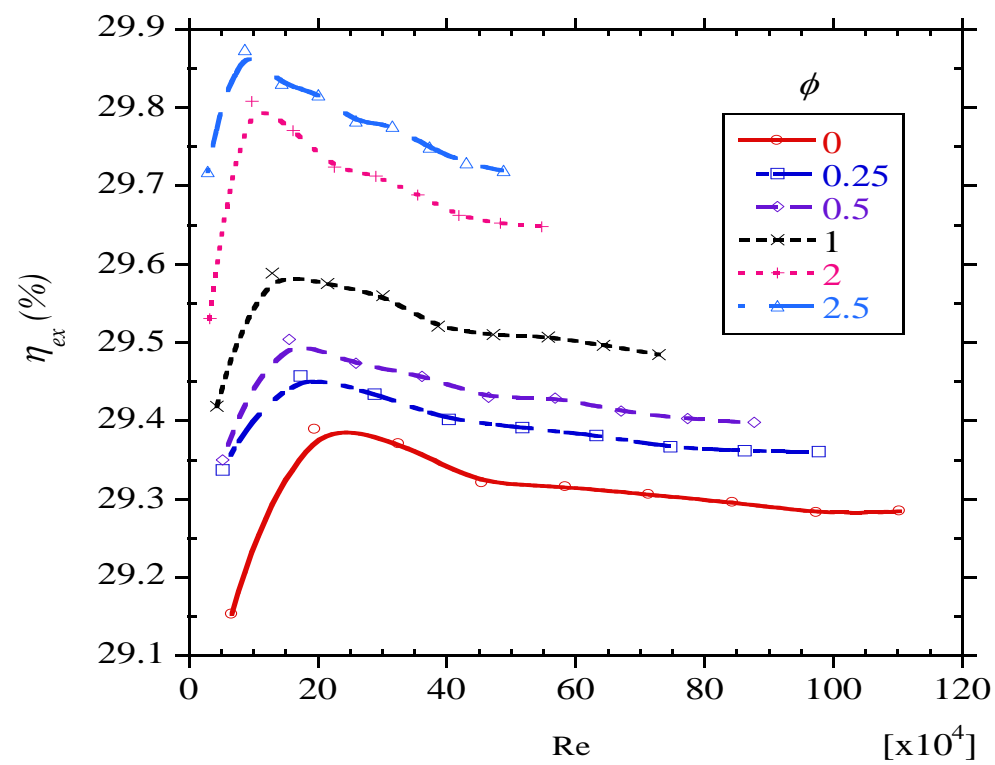

(a)

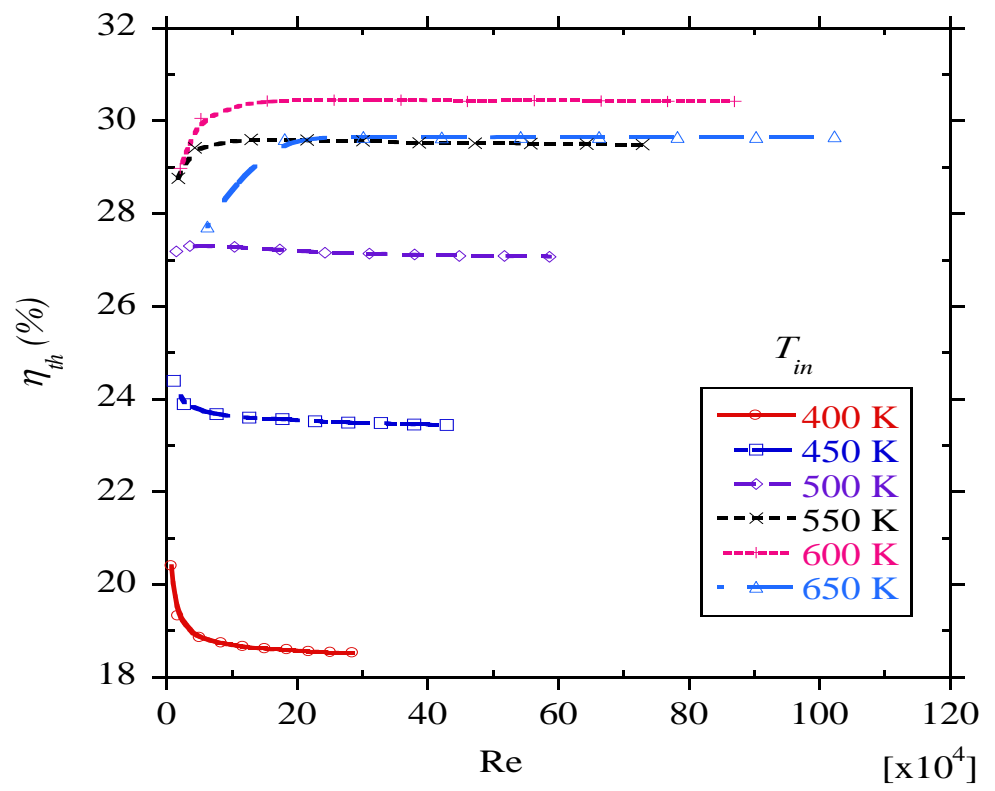

(b)

Fig. 15. Exergetic efficiency as a function of Reynolds number (a) and volume fraction at $T_{\text {in }}=550 \mathrm{~K}$, and (b) inlet temperature at $\varphi=1 \%$

rather on the inlet temperature as shown in Fig. 15(b). At low temperatures, the exergetic efficiency reduces as the Reynolds number increases. This is because the irreversibilities are higher at low temperatures and increase with Reynolds number, while the thermal losses are lower. This means a continuous reduction of the available energy and thus the exergetic efficiency. At higher temperatures, the irreversibililities are lower, but they increase with 
increasing Reynolds number. However, thermal losses are higher, such that increasing the flow rates reduces these irreversibilities and serves to increase the available energy. As the Reynolds number increases further, the fluid flow irreversibility increases and leads to drop of the exergetic efficiency. The magnitude of the drop depends on the volume fraction employed. The exergetic efficiency generally reduces with Reynolds number for temperatures lower than $500 \mathrm{~K}$, but increases above this temperature, reaches a maximum and drops as the Reynolds numbers increase. It has also shown that the exergetic efficiency increases with increasing inlet temperature, it reaches the top at about $600 \mathrm{~K}$ and starts to reduce thereafter as the temperatures increase further. The reduction at higher temperatures is probably due to the reduction in the available energy, i.e. higher thermal losses.

\section{Conclusion}

In this paper, the performance of a PTSC system using SWCNTs in Therminol®VP-1 has been numerically investigated. The energetic and exergetic performance of this system with a geometric concentration of 113 has been determined and presented for nanotube volume

fractions of $0.25,0.5,1$, and $2.5 \%$, and inlet temperatures ranging from $400 \mathrm{~K}$ to $650 \mathrm{~K}$. From the study, the following findings have been obtained as

i. It is worth noting that the heat transfer performance can be enhanced about $234 \%$ using SWCNTs compared to that of the case using base fluid only for the range of parameters considered in this study.

ii. Despite the mentioned improvement in the heat transfer performance, attributed to the high thermal conductivity of SWCNTs, it did not lead to higher improvements in the thermal efficiency. The thermal efficiency increased by up to $4.4 \%$ as the nanoparticle volume fraction increased from 0 to $2.5 \%$. Reasonable improvements in the thermal efficiency were seen to occur at the flow rates lower than $28 \mathrm{~m}^{3} \mathrm{~h}^{-1}$.

iii. The maximum temperature gradient on the receiver tube was reduced by about $35 \%$, substantial reductions are especially observed at low Reynolds number, as the volume fraction increases from 0 to $2.5 \%$.

iv. For the range of parameters considered, use of SWCNT nanofluid was shown to increase the exergetic performance of the PTSC system. Reduction in the entropy generation rate up to 
$70 \%$ was demonstrated due to the significant increase in the heat transfer performance and the subsequent reduction in the finite temperature difference.

v. It was also demonstrated that higher thermal conductivity does not necessarily mean higher thermal efficiency or energy output. The specific heat capacity needs to be considered as another important property in determining the thermal performance of such thermal energy systems using nanofluids.

\section{ACKNOWLEDGEMENT}

This work is based on the research supported in part by the National Research Foundation of South Africa (Grant No. 9927). This support is duly acknowledged and appreciated. Dr. Mwesigye acknowledges the support received from the school of Mechanical, Industrial and Aeronautical Engineering at the University of the Witwatersrand, Dr. Y1lmaz acknowledges the support received from the Department of Automotive Engineering at Adana Science and Technology University and Prof. Meyer duly acknowledges the support received from the University of Pretoria.

\section{REFERENCES}

[1] Yilmaz İH, Söylemez MS. Design and computer simulation on multi-effect evaporation seawater desalination system using hybrid renewable energy sources in Turkey. Desalination 2012;291:23-40.

[2] IEA. Key Renewables Trends. Excerpt from Renewables information (2016 edition) 2016:112.

[3] SunShot Initiative. Available at: http://www1.eere.energy.gov/solar/sunshot/index.html. US Department of Energy [Accessed 01.02.2016]

[4] SunShot Initiative-High-concentration low cost parabolic trough system for baseload CSP. Available at: http://www1.eere.energy.gov/solar/sunshot/csp_baseload_skyfuel.html. US Department of Energy [Accessed 01.12.2014].

[5] Price H, Lüpfert E, Kearney D, Zarza E, Cohen G, Gee R, Mahoney R. Advances in parabolic trough solar power technology. Sol Energy Eng 2002;124:109-25.

[6] Mark M, Craig T, Judith V, Michael W, Zhiwen M, Clifford H et al. Concentrating solar power Gen3 demonstration roadmap. NREL January 2017;NREL/TP-5500-67464:1-127.

[7] Philibert C, Frankl P. International Energy Agency, Technology roadmap: concentrating solar power. Paris, France: IEA/OECD, 2010. 
[8] Mark M, Craig T, Jennie J, Paul D, Clifford H, Kenneth A. On the path to SunShot: Advancing concentrating solar power technology, performance, and dispatchability. National Renewable Energy Laboratory and Sandia National Laboratories 2016; NREL/TP-550065688/SAND2016-2237 R:1-51.

[9] Solutia technical bulletin 7239115C. Available at:

https://www.therminol.com/products/Therminol-VP1 [Accessed 05.04.2016].

[10] Syltherm800 heat transfer fluid: product technical data. Available at:

http://www.dow.com/heattrans/products/synthetic/syltherm.htm [Accessed 18.05.2016].

[11] Fuqiang W, Ziming C, Jianyu T, Yuan Y, Yong S, Linhua L. Progress in concentrated solar power technology with parabolic trough collector system: A comprehensive review. Renewable and Sustainable Energy Reviews 2017;79:1314-28.

[12] Bellos E, Tzivanidis C. Parametric investigation of nanofluids utilization in parabolic trough collectors. Thermal Science and Engineering Progress 2017;2:71-9.

[13] Mwesigye A, Huan Z, Meyer JP. Comparative thermal performance of a parabolic trough receiver With $\mathrm{Cu}$-Therminol ${ }^{\circledR}$ VP-1, Ag-Therminol ${ }^{\circledR}$ VP-1 and Al2O3-Therminol ${ }^{\circledR}$ VP-1 Nanofluids. In conference proceedings of ASME 2016 International Mechanical Engineering Congress and Exposition, Phoenix, Arizona, USA, November 11-17, 2016. V008T10A073-.

[14] Sokhansefat T, Kasaeian AB, Kowsary F. Heat transfer enhancement in parabolic trough collector tube using Al2O3/synthetic oil nanofluid. Renewable and Sustainable Energy Reviews 2014;33:636-44.

[15] Basbous N, Taqi M, Belouaggadia N. Numerical study of a parabolic trough collector using a nanofluid. Asian Journal of Current Engineering and Maths 2015;4:40-4.

[16] Bellos E, Tzivanidis C, Antonopoulos KA, Gkinis G. Thermal enhancement of solar parabolic trough collectors by using nanofluids and converging-diverging absorber tube. Renewable Energy 2016;94:213-22.

[17] Wang Y, Xu J, Liu Q, Chen Y, Liu H. Performance analysis of a parabolic trough solar collector using Al2O3/synthetic oil nanofluid. Appl Therm Eng 2016;107:469-78.

[18] Kaloudis E, Papanicolaou E, Belessiotis V. Numerical simulations of a parabolic trough solar collector with nanofluid using a two-phase model. Renewable Energy 2016;97:218-29.

[19] Ghasemi SE, Ranjbar AA. Thermal performance analysis of solar parabolic trough collector using nanofluid as working fluid: A CFD modelling study. Journal of Molecular Liquids 2016;222:159-66.

[20] Coccia G, Di Nicola G, Colla L, Fedele L, Scattolini M. Adoption of nanofluids in lowenthalpy parabolic trough solar collectors: Numerical simulation of the yearly yield. Energy Conversion and Management 2016;118:306-19.

[21] Mwesigye A, Huan Z. Thermal and thermodynamic performance of a parabolic trough receiver with Syltherm800-Al2O3 nanofluid as the heat transfer fluid. Energy Procedia 2015;75:394-402. 
[22] Mwesigye A, Huan Z, Meyer JP. Thermal performance and entropy generation analysis of a high concentration ratio parabolic trough solar collector with $\mathrm{Cu}$-Therminol@VP-1 nanofluid. Energy Conversion and Management 2016;120:449-65.

[23] Mwesigye A, Meyer JP. Optimal thermal and thermodynamic performance of a solar parabolic trough receiver with different nanofluids and at different concentration ratios. Appl Energy 2017;193:393-413.

[24] de Risi A, Milanese M, Laforgia D. Modelling and optimization of transparent parabolic trough collector based on gas-phase nanofluids. Renewable Energy 2013;58:134-9.

[25] Kasaeian A, Daneshazarian R, Pourfayaz F. Comparative study of different nanofluids applied in a trough collector with glass-glass absorber tube. Journal of Molecular Liquids 2017;234:315-23.

[26] Sunil K, Kundan L, Sumeet S. Performance evaluation of a nanofluid based parabolic solar collector-An experimental study. International Journal of Mechanical and Production Engineering 2014;2:61-7.

[27] Kasaeian A, Daviran S, Azarian RD, Rashidi A. Performance evaluation and nanofluid using capability study of a solar parabolic trough collector. Energy Conversion and Management 2015;89:368-75.

[28] Said Z, Saidur R, Rahim NA, Alim MA. Analyses of exergy efficiency and pumping power for a conventional flat plate solar collector using SWCNTs based nanofluid. Energy Build 2014;78:1-9.

[29] Sabiha MA, Saidur R, Hassani S, Said Z, Mekhilef S. Energy performance of an evacuated tube solar collector using single walled carbon nanotubes nanofluids. Energy Conversion and Management 2015;105:1377-88.

[30] Duffie JA, Beckman WA. Solar engineering of thermal processes. 3rd ed. Hoboken, New Jersey: John Wiley and Sons Inc., 2006.

[31] Soteris K. Solar Energy Engineering: Processes and Systems. 2nd ed. United Kingdom: Academic Press, 2013.

[32] Li J, Wang Z, Lei D, Li J. Hydrogen permeation model of parabolic trough receiver tube. Sol Energy 2012;86:1187-96.

[33] Moens L, Blake DM. Mechanism of hydrogen formation in solar parabolic trough receivers. J Sol Energ-T ASME 2010;132:031006.

[34] Mwesigye A, Bello-Ochende T, Meyer JP. Heat transfer and entropy generation in a parabolic trough receiver with wall-detached twisted tape inserts. International Journal of Thermal Sciences 2016;99:238-57.

[35] Mwesigye A, Huan Z, Bello-Ochende T, Meyer JP. Influence of optical errors on the thermal and thermodynamic performance of a solar parabolic trough receiver. Solar Energy 2016;135:703-18.

[36] Mwesigye A, Bello-Ochende T, Meyer JP. Minimum entropy generation due to heat transfer and fluid friction in a parabolic trough receiver with non-uniform heat flux at different rim angles and concentration ratios. Energy 2014;73:606-17. 
[37] Çengel YA, Ghajar AJ. Heat and mass transfer: fundamentals \& applications. 4th ed. New York: McGraw-Hill, 2011.

[38] Kock F, Herwig H. Local entropy production in turbulent shear flows: a high-Reynolds number model with wall functions. Int J Heat Mass Trans 2004;47:2205-15.

[39] Herwig H, Kock F. Direct and indirect methods of calculating entropy generation rates in turbulent convective heat transfer problems. Heat and Mass Transfer 2007;43:207-15.

[40] Petela R. Exergy of undiluted thermal radiation. Solar Energy 2003;74:469-88.

[41] Petela R. Engineering thermodynamics of thermal radiation for solar power utilization. 2010:399.

[42] Alashkar A, Gadalla M. Thermo-economic analysis of an integrated solar power generation system using nanofluids. Appl Energy 2017;191:469-91.

[43] Pop E, Mann D, Wang Q, Goodson K, Dai H. Thermalconductance of an individual singlewall carbon nanotube above room temperature. Nano Lett 2006;6:96-100.

[44] Incropera P. Frank, DeWitt P. David, Bergman L. Theodore, Lavine S. Adrienne. Fundamentals of heat and mass transfer. 6th ed. US: John Wiley \& Sons, 2006.

[45] Aldrich Carbon nanotube, single-walled 40-60 wt. \% carbon basis, D $\times$ L 2-10 nm $\times 1$ $5 \mu \mathrm{m}$ bundle dimensions. Available at

http://www.sigmaaldrich.com/catalog/product/aldrich/704113?lang=en\&region=ZA [Accessed 08.04.2017].

[46] Jo B, Banerjee D. Enhanced specific heat capacity of molten salt-based carbon nanotubes nanomaterials. Journal of Heat Transfer 2015;137:091013,091013-7.

[47] Manca O, Mesolella P, Nardini S, Ricci D. Numerical study of a confined slot impinging jet with nanofluids. Nanoscale Res Lett 2011;6:188,276X-6-188.

[48] Li P, Zhang D, Xie Y. Heat transfer and flow analysis of Al2O3-water nanofluids in microchannel with dimple and protrusion. Int J Heat Mass Transfer 2014;73:456-67.

[49] Einstein A. Investigations on the theory of the Brownian movement. New York: Dover Publications, 1956.

[50] Xing M, Yu J, Wang R. Experimental study on the thermal conductivity enhancement of water based nanofluids using different types of carbon nanotubes. Int $\mathbf{J}$ Heat Mass Transfer 2015;88:609-16.

[51] Xing M, Yu J, Wang R. Thermo-physical properties of water-based single-walled carbon nanotube nanofluid as advanced coolant. Appl Therm Eng 2015;87:344-51.

[52] Hamilton RL, Crosser OK. Thermal conductivity of heterogeneous two-component systems. Industrial and Engineering Chemistry Fundamentals 1962;1:187-91.

[53] Nan C, Liu G, Lin Y, Li M. Interface effect on thermal conductivity of carbon nanotube composites. Appl Phys Lett 2004;85:3549-51.

[54] Choi SUS, Zhang ZG, Yu WL,F. E., Grulke EA. Anomalous thermal conductivity enhancement in nanotube suspensions. Appl Phys Lett 2001;79:2252-4. 
[55] Selvam C, Harish S, Lal DM. Effective thermal conductivity and rheological characteristics of ethylene glycol-based nanofluids with single-walled carbon nanohorn inclusions. Fullerenes, Nanotubes and Carbon Nanostructures 2017;25:86-93.

[56] Baratpour M, Karimipour A, Afrand M, Wongwises S. Effects of temperature and concentration on the viscosity of nanofluids made of single-wall carbon nanotubes in ethylene glycol. International Communications in Heat and Mass Transfer 2016;74:108-13.

[57] Halelfadl S, Estellé P, Aladag B, Doner N, Maré T. Viscosity of carbon nanotubes waterbased nanofluids: Influence of concentration and temperature. International Journal of Thermal Sciences 2013;71:111-7.

[58] Bobbo S, Fedele L, Benetti A, Colla L, Fabrizio M, Pagura C, Barison S. Viscosity of water based SWCNH and TiO2 nanofluids. Experimental Thermal and Fluid Science 2012;36:65-71.

[59] Halelfadl S, Maré T, Estellé P, Mohd-Ghazali N. Experimental investigation of rheological behavior and pessure drop of aqueous suspensions of carbon nanotubes in a horizontal tube. Procedia Engineering 2013;56:344-9.

[60] Aladag B, Halelfadl S, Doner N, Maré T, Duret S, Estellé P. Experimental investigations of the viscosity of nanofluids at low temperatures. Applied Energy 2012;97:876-80.

[61] Li Q, Zheng C, Mesgari S, Hewkuruppu YL, Hjerrild N, Crisostomo F, Rosengarten G, Scott JA, Taylor RA. Experimental and numerical investigation of volumetric versus surface solar absorbers for a concentrated solar thermal collector. Solar Energy 2016;136:349-64.

[62] Mesgari S, Taylor RA, Hjerrild NE, Crisostomo F, Li Q, Scott J. An investigation of thermal stability of carbon nanofluids for solar thermal applications. Solar Energy Materials and Solar Cells 2016;157:652-9.

[63] Forristall R. Heat transfer analysis and modeling of a parabolic trough solar receiver implemented in Engineering Equation solver. NREL Technical Report, October 2003; NREL/TP-550-34169:1-145.

[64] Burkholder F, Kutscher C. Heat loss testing of Schott's 2008 PTR70 parabolic trough receiver. NREL Technical Report, 2009;NREL/TP - 550-45633:1-58.

[65] ANSYS ${ }^{\circ}$ Academic research, release 17.1, ANSYS FLUENT, theory guide, ANSYS, Inc.

[66] ANSYS® Academic research, release 17.1, ANSYS FLUENT user's guide, ANSYS, Inc.

[67] NREL. SolTrace optical modelling software. SolTrace 2012;2012.7.9.

[68] Wendelin T. Parabolic trough VSHOT optical characterization in 2005-2006. Parabolic trough technology workshop. Incline Village, Nevada, $14^{\text {th }}-16^{\text {th }}$ February 2006, NREL/PR-55040024.

[69] Mullick SC, Nanda SK. An improved technique for computing the heat loss factor of a tubular absorber. Solar Energy 1989;42:1-7.

[70] Swinbank WC. Long-wave radiation from clear skies. Q J R Meteorol Soc 1963;89:339-48.

[71] [66] Schott's PTR70 Receiver. Available at: http://www.schott.com/csp/english/schott-solarptr-70-receivers.html [Accessed 24.09.2016]. 
[72] Mwesigye A, Bello-Ochende T, Meyer JP. Numerical investigation of entropy generation in a parabolic trough receiver at different concentration ratios. Energy 2013;53:114-27.

[73] Jeter SM. Calculation of the concentrated flux density distribution in parabolic trough collectors by a semifinite formulation. Solar Energy 1986;37:335-45.

[74] Dudley EV, Kolb JG, Mahoney AR, Mancini T, R., Sloan M, Kearney D. Test results: SEGS LS-2 solar collector. Sandia National Laboratory 1994;SAND94-1884.

[75] Dreyer S, Eichel P, Gnaedig T, Hacker Z, Janker S, Kuckelkorn T, Silmy K, Pernpeintner J, Luepfert, E. Heat loss measurements on parabolic trough receivers. SolarPACES 2010.

[76] Yılmaz İH, Söylemez MS. Thermo-mathematical modeling of parabolic trough collector. Energy Conversion and Management 2014;88:768-84.

[77] Bejan A. Entropy generation minimization: the method of thermodynamic optimization of finite-size systems and finite-time processes. Boca Raton, Fla.: CRC Press, 1996. 